\title{
Sexual behaviour, debut and identity among Swedish Schoolchildren
}

\author{
Åsa A. Kastbom
}

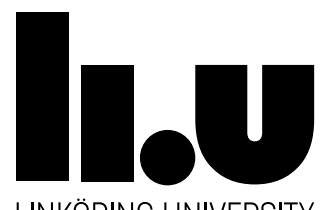

LINKÖPING UNIVERSITY

Faculty of Medicine and Health Sciences

Department of Clinical and Experimental Medicine

Linköping University

SE-581 83 Linköping, Sweden 
(C) Åsa A. Kastbom 2015

ISBN 978-91-7685-953-7

ISSN 0345-0082

Printed by LiU-Tryck, Linköping, Sweden 2015 
Till minne av Stefan Croner 



\section{TABLE OF CONTENTS}

$\begin{array}{ll}\text { ABSTRACT } & 9\end{array}$

SAMMANFATTNING PÅ SVENSKA 11

$\begin{array}{ll}\text { LIST OF PAPERS } & 15\end{array}$

$\begin{array}{ll}\text { ABBREVIATIONS } & 16\end{array}$

$\begin{array}{ll}\text { Personal points of departure } & 17\end{array}$

$\begin{array}{ll}\text { INTRODUCTION } & 17\end{array}$

$\begin{array}{ll}\text { Background to the thesis } & 17\end{array}$

$\begin{array}{ll}\text { The Swedish context } & 20\end{array}$

$\begin{array}{ll}\text { Sexual development } & 22\end{array}$

Background to sexual development $\quad 22$

Sexual development and attachment $\quad 24$

$\begin{array}{ll}\text { Sexual development during childhood } & 27\end{array}$

Sexual development during preadolescence $\quad 29$

Sexual development during adolescence $\quad 30$

$\begin{array}{ll}\text { Sexual identity } & 32\end{array}$

$\begin{array}{ll}\text { Sexual behaviours } & 34\end{array}$

Research on childrens' sexual behaviours 34

Common sexual behaviours 36

$\begin{array}{ll}\text { Uncommon sexual behaviours } & 37\end{array}$

Sexual risk behaviours $\quad 38$

The sexual debut $\quad 39$

Sexuality and the online culture $\quad 42$ 
Aims

Study I

Study II

Study III

Study IV

Methods

Study I

Study II-IV

Results \& Discussion

Study I

Study II

Study III 70

Study IV

GENERAL DISCUSSION

Summary of findings and clinical implications and reflections

Common and uncommon sexual behaviours among school children

Sexual debut age and its associations with mental health and risk behaviours

Sexual debut age, sexual identity and its associations with child abuse 83

Sexual debut age, sexual identity and its associations with sexual exploitation 85 Methodological considerations and limitations 
Ethical considerations

Suggestions for future work

ACKNOWLEDGEMENTS

91

REFERENCES 



\section{ABSTRACT}

Background: Sexual behaviour among schoolchildren and adolescents is a sparsely researched area and there are delicate methodological obstacles and ethical concerns when conducting such research. Still it is a subject that engages both parents and professionals. A sexualized behaviour or an early sexual debut (younger than 14 years) can be a sign of sexual abuse. It is therefore of importance to describe what is common and what is uncommon sexual behaviour among children and what the consequences of an early or a late sexual debut may be for the individual upon reaching late adolescence. Adolescents who identify themselves as lesbian, gay or bisexual (LGB) are also a group that needs further attention and research since they are often described as having a lower quality of life and more often experience child abuse than heterosexual teens.

Aims: The research leading to this thesis had four goals: 1) to elucidate the sexual behaviour of children between the ages of 7 and 13 as observed by their parents, 2) to investigate the relationship between an early sexual debut (before 14 years of age) and socio-demographic data, sexual experience, health, experience of child abuse and behaviour at 18-years-of-age, 3) to explore associations with no sexual debut (no oral, vaginal or anal sex) at the age of 18 , and 4) to describe the relationship between sexual identification and socio-demographic background data, sexual behaviour, health and health behaviour, experiences of child sexual and/or physical abuse and present behaviour among Swedish adolescents.

Methods: The parents of 418 children answered questionnaires about their child's behaviour, both general and sexual, and a sample of 3432 Swedish high school students completed a survey about sexuality, health and abuse at the age of 18. In addition, 362 members of the Swedish Federation for Lesbian, Gay, Bisexual and Transgender Rights (RFSL) completed the same survey at a mean age of 21.4 years.

Results: Most of the sexual behaviours among the schoolchildren were common, and in part related to, or varied with, age and gender. A small number of sexual behaviours often referred to as sexualised or problematic behaviours (for example, kissing adults with the tongue, imitating intercourse, masturbating in public, and touching other children's genitals with the mouth) were found to be very unusual or not reported by any parent in this normative group of Swedish children. Among the adolescents, an early debut (younger than 14 years of age) correlated positively with number of partners, experience of oral and anal sex, smoking, drug and alcohol use and antisocial behaviour, such as being violent, lying, stealing and running away from home. Girls with an early sexual debut had significantly more experience of sexual 
abuse while boys with an early sexual debut were more likely to have a weak sense of coherence, low self-esteem and poor mental health, together with experience of sexual abuse, selling sex and physical abuse. A multiple logistic regression model showed that a number of antisocial acts and health behaviours remained significant, but early sexual debut did not increase the risk of psychiatric symptoms, low self-esteem or low sense of coherence at 18years-of-age. Just under a quarter $(24.6 \%)$ of the 3,380 adolescents had not had their sexual debut (no oral, anal or vaginal sex by the age of 18). There was a positive correlation between not debuting sexually at age 18 and a number of factors such as: being more likely to have caring fathers; parents born outside Europe; low sexual desire; lower pornography consumption; lower alcohol and tobacco consumption; less antisocial behavior and fewer experiences of sexual abuse than 18 year olds who had already made their sexual debut. Adolescents with a minority sexual identity more often described their relationship with their parents as based on low care and high overprotection than did their heterosexual peers. The minority adolescents used alcohol and drugs to a significantly higher degree than the heterosexual adolescents. Multivariate analysis showed a positive correlation between a minority sexual identity and experience of anal sex, higher sexual lust, experience of sexual abuse, physical abuse and sexual exploitation. It was more than twice as common to have experience of penetrating sexual abuse and physical abuse with a sexual minority identity. Conclusions: Behaviours usually referred to as sexualised and problematic are uncommon among children at 7-13 years of age. Professionals and should give a child showing a sexualised behaviour special attention and investigate the reasons for the behaviour. Early sexual debut seems to be associated with problematic behaviours during later adolescence, indicating the fact that the early debut for some children is associated with an increased vulnerability, which has to be addressed. Family socio-demographics such as family stability and/or cultural status matter when it comes to time of sexual debut. Personality also seems to matter and further studies are needed to investigate if there is any correlation between personality traits and late sexual debut. Adolescents with no sexual debut at 18 years of age reported fewer antisocial acts, were less likely to smoke and drink alcohol, had less sexual desire and less experience of sexual abuse. Young people with a sexual minority identity (homo- and bisexual) could be seen to have a lower quality of life compared to heterosexual peers and studies need to be done to further explore possible reasons. They have a higher risk of having experience of sexual and physical abuse compared to heterosexual adolescents. Professionals need to be more aware of this group's additional vulnerability including the increased risk of child abuse and offer different forms of support. 


\section{SAMMANFATTNING PÅ SVENSKA}

Barns och ungdomars sexuella beteenden är ett område som engagerar både föräldrar och professionella men det är ett förhållandevis outforskat område. Kanske mycket på grund av att det är ett tabubelagt område och att finns en hel del metodologiska hinder och etiska betänkligheter vid sådan forskning.

Ett sexualiserat beteende kan vara tecken på sexuella övergrepp och det är därför viktigt att beskriva vad som är vanligt förekommande och förväntade sexuella beteenden hos barn och unga tillika vilka beteenden som är ovanliga och som kanske behöver utredas vidare. En tidig sexuell debut (debut före 14 års ålder) kan ses som ett riskbeteende i sig men även ett beteende kopplat till andra riskbeteenden som alkoholkonsumtion eller antisociala beteenden. Att vänta med den sexuella debuten beskrivs ibland som något önskvärt men det är inte särskilt väl utforskat. Därför är det viktigt att ta reda på vilka konsekvenser en tidig eller sen sexuell debut får för individen och vilka andra beteenden som är kopplade till en tidig eller sen sexuell debut.

Ett annat viktigt område när det gäller ungdomar och sexualitet är sexuell identitet och dess konsekvenser. Ungdomar med en sexuell identitet som homo-, bisexuell eller transperson (HBT) beskrivs i tidigare forskning ofta uppleva en lägre livskvalitet samt oftare ha erfarenhet av barnmisshandel än jämnåriga med heterosexual identitet.

Studierna i denna avhandling hade fyra huvudsyften: 1), att undersöka sexuella beteenden hos barn i åldrarna 7 till 13 år 2,) att undersöka sambanden mellan en tidig sexuell debut (yngre än 14 år) och sociodemografi, sexuella erfarenheter, hälsa, erfarenhet av barnmisshandel och beteende vid 18 års ålder 3), sen sexuell debut (ingen frivillig erfarenhet av oral-, vaginaleller analsex vid 18 års ålder) och sociodemografi, sexuella erfarenheter, hälsa, erfarenhet av barnmisshandel och beteende vid 18 års ålder samt 4), att beskriva relationen mellan sexuell identitet och sociodemografi, sexuellt beteende, hälsa, erfarenheter av barnmisshandel och nuvarande beteenden hos svenska 18-åringar.

Föräldrarna till 418 barn i åldern 7 till 13 år svarade på en enkät angående deras barns generella och sexuella beteenden. För att undersöka ungdomars sexuella beteenden, debut och identitet genomfördes en undersökning bland 3432 svenska gymnasieelever i 18-års ålder. Dessutom svarade 362 medlemmar i Svenska Förbundet för homosexuellas, bisexuellas och transpersoners rättigheter (RFSL), med en medelåder på 21.4 år, på samma enkät. 
Det visade sig att många sexuella beteenden bland 7 till 13-åringarna var vanligt förekommande och att de varierade i frekvens med ålder och kön. Problematiska eller oroväckande sexuella beteenden (som till exempel att kyssa vuxna med tungan, imitera samlag, onanera inför andra, röra andras könsorgan med munnen och så vidare) rapporterades inte av några föräldrar eller var mycket ovanliga. En tidig sexuell debut (yngre än 14 år) korrelerade positivt med högre antal sex partner, erfarenhet av oral- och analsex, rökning, drog- och alkoholanvändning och antisocialt beteende, såsom våldsbenägenhet, att ljuga, stjäla och sova borta utan att föräldrarna vet om det. Flickor med en tidig sexuell debut hade större erfarenhet av sexuella övergrepp än flickor med senare debut. Pojkar med en tidig sexuell debut hade oftare en svag känsla av sammanhang, låg självkänsla, psykisk ohälsa, erfarenhet av sexuella övergrepp, att sälja sex eller fysisk misshandel jämfört med pojkar med en senare debut.

Knappt en fjärdedel $(24,6 \%)$ av de 3380 ungdomarna hade inte haft frivillig sexuell debut (oral-, anal- eller vaginalsex) vid 18 års ålder. Ungdomar med sen sexuell debut hade oftare en pappa-barn relation som byggde på en hög grad av omsorg. De hade oftare föräldrar födda utanför Europa, låg sexuell lust, låg pornografikonsumtion, låg alkohol- och tobakskonsumtion, få antisociala beteenden och mer sällan erfarenhet av sexuella övergrepp än 18-åringar som redan debuterat sexuellt.

Ungdomarna med sexuell identitet som homo- eller bisexuella hade oftare en föräldra-barn relation som byggde på låg omsorg och hög kontroll än sina heterosexuella kamrater. De homo-och bisexuella ungdomarna använde också mer alkohol och droger jämfört med de heterosexuella ungdomarna. Multivariat analys visade ett positivt samband mellan homo- och bisexualitet och erfarenhet av analsex, sexuell lust, erfarenhet av sexuella övergrepp, misshandel och erfarenhet att sälja sex. Det var mer än dubbelt så vanligt att ha erfarenhet av sexuella övergrepp och fysisk misshandel hos de med en sexuell minoritets identitet.

En av slutsatserna blev att översexualiserade eller problematiska sexuella beteenden är sällsynta hos barn i 7-13 års ålder. Det är viktig kunskap för professionella som arbetar med barn och som ofta får frågor kring barns olika beteenden och måste avgöra om det är förväntade och vanligt förekommande beteenden eller beteenden som ska leda till någon form av utredning, Om ett barn visar ett översexualiserat eller annorlunda sexuellt beteende ska det observeras och undersökas vidare av professionella med kunskap om barn och dess utveckling. 
Tidig sexuell debut verkar vara förknippad med andra problematiska beteenden under senare tonåren. Detta kan också tyda på att den tidiga debuten för vissa barn är associerat med en ökad sårbarhet, som också måste identifieras och tillgodoses av olika yrkeskategorier som arbetar med barn och ungdomar.

Det finns olika anledningar till varför vissa ungdomar inte haft sexuell debut vid 18 års ålder. Faktorer som familjestabilitet och kulturell bakgrund spelade roll. Ungdomar med sen sexuell debut rapporterade färre antisociala handlingar, var mindre benägna att röka och dricka alkohol, hade mindre sexuell lust och mindre erfarenhet av sexuella övergrepp. Ytterligare studier behövs för att undersöka om det finns något samband mellan personlighetsdrag och sen sexuell debut.

Ungdomar med en sexuell identitet som homo- eller bisexuell skulle kunna anses ha en lägre livskvalitet jämfört med heterosexuella kamrater men ytterligare studier måste göras för att ytterligare utforska möjliga orsaker. Det visade sig vara mycket vanligare med erfarenhet av såväl fysisk misshandel som sexuella övergrepp bland dessa ungdomar. Vuxna och framför allt professionella behöver bli mer medvetna om denna grupps sårbarhet, den ökade risken för erfarenhet av barnmisshandel och kunna erbjuda olika former av stöd. 


\section{LIST OF PAPERS}

\section{Paper I}

Kastbom AA, Larsson I \& Svedin CG. (2012) Parents'reports on 7- to 13-year old children's sexual behaviour. Reproductive System \& Sexual Disorders 1:2,1-7

\section{Paper II}

Kastbom AA, Bladh M, Sydsjo G, Priebe G \& Svedin CG. (2015) Sexual debut before the age of 14 leads to poorer psychosocial health and risky behaviour in later life. Acta Paediatrica 104(1):91-100 doi:10.1111/apa.12803

\section{Paper III:}

Kastbom AA, Sydsjo G, Bladh M, Priebe G \& Svedin CG. (2015) Differences in sexual behaviors, health and history of child abuse among school students who did and did not not engage in sexual activity by the age of 18: a cross sectional study. Adolescent Health, Medicine and Therapeutics in press

\section{Paper IV}

Kastbom AA, Sydsjo G, Bladh M, Priebe G \& Svedin CG. Sexual minorities and quality of life - a descriptive study among Swedish adolescents. Submitted to Sexual \& Reproductive Healthcare, October 2015. 


\section{ABBREVIATIONS}

ACC: Anterior cingulate cortex

CSA: Child Sexual Abuse

CSBI: Child Sexual Behaviour Inventory

DSM: Diagnostic and Statistical Manual of Mental Disorders

FtM: Female to male

HBT: Homo-, bisexuell eller transperson

IRMA: The Illinios Rape Myth Acceptance Scale

IRMA-SF: Illionis Rape Myth Acceptance Scale, short form

LGB: Lesbian, gay or bisexual

LGBT: Lesbian, gay, bisexual and transperson

MtF: Male to female

PBI: The Parental Bonding Instrument

RFSL: Swedish Federation for Lesbian, Gay, Bisexual and Transgender Rights

SCL-25: Symptom Checklist

STI: Sexually transmitted infection

SDQ: Strength and Difficulties Questionnaire (SDQ)

SOC: The Sense of Coherence scale

WHO: World Health Organization 


\section{Personal points of departure}

The starting point for my research was my interest in and work with sexually abused children as a clinician. I often received questions from professionals in different areas whether a child's behaviour could be a sign of sexual abuse or not and the most common question was and still is if the behaviour is normal or not. Behaviours can be described as normal or not normal but in my work and in this thesis I choose to describe the behaviours as common or uncommon. There are no typical symptoms or set of sexual behaviours that stand for sexual abuse but there are behaviours that need extra attention from adults and professionals. An early sexual debut is often labelled as risk behaviour and a possible sign of sexual abuse and a late sexual debut is often described as something positive. As a clinician I also often get questions about adolescents with a minority sexual identity and their vulnerable position in society including experience of sexual abuse, risk behaviours as drug and alcohol use and anti-social behaviours.

In this thesis I describe which sexual behaviours are common and uncommon among 7 to 13 year old children, different associations with both early sexual debut (younger than 14 years of age) and no sexual debut at the age of 18 and also different aspects of having a minority sexual identity.

\section{INTRODUCTION}

\section{Background to the thesis}

Sexuality and sexual behaviour among children and adolescents engage parents, society and professionals. Many in each group often ask what is normal sexual behaviour and what is not normal, what is deviant or may be a sign of a child or adolescent in need. The term normal or normality has been functionally and differentially defined by researchers in a vast number of disciplines and the terms are complex and contested (Tolman \& McClelland, 2011). There is of course not one single definition, the definition varies by person, time, place and situation and often involves value judgments and is influenced by societal standards and norms. One example, the widely used Diagnostic and Statistical Manual of Mental Disorders (DSM) 
attempts to explicitly distinguish normality from abnormality based on specific symptoms (Horwitz, 2007). Barker instead defined normative as: pertaining to the average or expected behaviour patterns of a group or a community (Barker, 1995).

Adolescent sexuality has long been equated with danger (Moran, 2000) but Tolman and McClelland describe a shift during the start of the decade that began in 2000 (Tolman \& McClelland, 2011). Welsh, Rostosky and Kawaguchi (2000) noted that sexuality was slowly becoming understood as integral to adolescent identity and described a movement towards a more normative perspective. In 2004, researchers from different disciplines gathered for a conference with the title "Cutting the Edge of Research in Adolescent Sexuality: Considering Normative Development in the United States" to point out that adolescent sexuality is a normal and expected aspect of adolescent development (Tolman \& McClelland, 2011).

In this thesis the investigated sexual behaviours are described as common or uncommon (as frequent and infrequent); by making this distinction, the information may help adults or professionals get a better understanding of when they may need to react upon a sexual behaviour and give the child or the adolescent some extra attention.

The terms "sexual" and "sexuality" are often associated with adult sex (sexual intercourse or copulation) (Goldman \& Goldman, 1982, Vance, 1991) but those terms do not work well when it comes to discussing children's sexuality or sexual behaviour. In this field of research it is of great importance to emphasize that the differences between child sexuality and adult sexuality are not just based on the physical and physiological differences but arise from the children's lack of knowledge and cognitive inability to make sense of the world (Bergenheim, 1994; Jackson, 1982; Martinson 1994; Jackson, 1982). The term sexuality is used here in a broad sense related to its multidimensional nature and involving sexual identity, biology, physiology, attitudes, behaviours and activity.

Sexual behaviour among children is a sparsely researched area especially among young children, at least in part because there are delicate methodological obstacles and ethical concerns to be considered by all planning to conduct such research. Most of what is known of children's normal sexual behaviour has been obtained by observing children (parental or professional observation) or retrospective studies of young adults. 
A problematic sexualized behaviour may be a precursor to sexual offending (Wiekowski, Hartsoe, Mayer \& Shortz, 1998) or a sign of underlying emotional problems (Friedrich et al., 1992). The escalating concern about childhood sexual abuse during the past 20 years has evoked a tendency to view any sexual expression in children as evidence that a sexual violation must have occurred (Reynolds, Herbenick \& Bancroft, 2003). Children who has not been sexually abused can also express sexual feelings or behaviours (De Graaf \& Rademakers, 2006). As a result much research has therefore been focused on depicting the negative effects of sexual abuse, with far fewer studies focused on normative or common childhood sexuality. Of all publications in the PsychINFO Medline and Social SciSearch databases that combine child(ren) and sexual(ity) in their titles, only $1 \%$ do not treat sexual behaviour of children as either a part or a concequence of sexual abuse (De Graaf \& Rademakers, 2011) Further studies of children's sexual behaviour are therefore of great importance in adding to our knowledge about child sexual development as well as to determine what kind of behaviour is common and what is not.

Sexual behaviours among adolescents have also often been associated with negative life events, sexual risk behaviours, danger and negative consequences as unplanned pregnancies, sexually transmitted infections, (Moran, 2000). In spite of this, a positive change over the last 30 years has taken place as described by Tolman and McClelland (2011), a change resulting since some researchers have unlinked adolescent sexuality from assumed dangerous outcome and pathology (Bauman \& Udry, 1981; Ehrhart, 1996; Fine, 1988; Thompson, 1995).

Sexual behaviour in adolescents depends on various factors such as personality, gender, family stability, religiosity, ethnicity, onset of puberty, experience of child abuse etcetera. The most frequently examined indicator of risky sexual behaviour reported in the literature is young age at first intercourse (Lansford et al., 2010). An early sexual debut (younger than 14 years of age) is often described as a risk factor associated with a variety of other risk behaviours. A sexualized behaviour or an early sexual debut can be a sign of sexual abuse (Dahle et al, 2010; Pedersen \& Skrondal, 1996; Valle et al., 2009) and therefore it is of importance to describe what is sexualized or uncommon sexual behaviour among children and adolescents and what consequences an early or a late sexual debut has for the individual when reaching late adolescence. 
Adolescents with sexual identification as lesbian, gay or bisexual (LGB) are sometimes described as having a lower quality of life as well as more risky sexual behaviour than heterosexual teens (Mayer et al., 2014). Adolescents in sexual minority groups do not only need to face the challenge of the ordinary difficulties becoming an adult but also need to undergo the "coming out" process, especially if living in a hetero-normative context with not many role models with the same sexual orientation. It is therefore of value to investigate LGBs and their physical and psychological health including sexual behaviour and other present behaviours. In this thesis the adolescents' own interpretation of the term sexual identification was used when they answered the questionnaire in the study. The minority sexual identification groups were the ones consisting of all who answered homo- or bisexual when asked about their sexual identification even though we are aware that a person can experience strong same-sex attraction but self-identify as heterosexual.

The aim of the research leading to this thesis was to: 1) elucidate the sexual behaviour in children between the ages of 7 to 13 as observed by their parents (study I), 2) to investigate the relationship between an early sexual debut (debute at younger than 14 years) and family socio-demographics, sexual experience, health, experience of child abuse and behaviour at 18-years-of-age (study II), 3) to explore associations with no sexual debut (no oral, vaginal or anal sex) at the age of 18 (study III) and 4) to describe the relationship between sexual identity and family socio-demographics, sexual behaviour, health and health behaviour, experiences of child abuse and sexual abuse (study IV).

\section{The Swedish context}

Sexual health has been a public health matter in Sweden for many years. The first ever national study of sexual behaviour in Sweden was conducted in 1967 (Zetterberg, 1969) and the findings formed a basis for sex education programs in Swedish schools for many years. According to The World Health Organization (WHO) all human beings have the right to good sexual health. WHO defines sexual health as: a state of physical, emotional, mental and social well being in relation to sexuality; it is not merely the absence of disease, dysfunction or infirmity. Sexual health requires a positive and respectful approach to sexuality and sexual relationships, as well as the possibility of having pleasurable and safe sexual experiences, 
free of coercion, discrimination and violence. For sexual health to be attained and maintained, the sexual rights of all persons must be respected, protected and fulfilled (WHO, 2006). In Sweden there has been a tradition of tolerance and a positive attitude towards sexuality among adolescents and the government declared in a bill passed in 2007 that sexual health is one of eleven goals promoting public health. Goal number eight was called "Safe sexuality and good reproductive health and was intended to work as a guide to promoting good sexual health in Sweden. To promote better sexual health among both adolescents and adults, approaches need to address gender equality, sexual education programs, attention to inequalities, the right to contraceptives, safe abortions, prenatal care, medical care for new born, protection from sexually transmitted infections (STI), and freedom from genital mutilation as well as sexual and other gender-related violence (Proposition, 2007/08:110). Sexual education in Swedish schools became compulsory in 1955 and is incorporated in all appropriate subjects in the Swedish curriculum for primary schools (Skolverket, 2014). The first specialized clinic for adolescents and their sexual health (Ungdomsmottagning) opened in Sweden in 1970. Today there are 218 clinics and there are also many different web sites where adolescents can find information about sexuality, health and relationships. One of the best known websites for Swedish youth is: www.umo.se with approximately 570000 visitors every month. At the website it is possible to ask questions anonymously and the site provides contact with midwives, nurses, counsellors, doctors, psychologists and dieticians who can answer questions.

It has always been quite acceptable in Sweden to talk to children and teenagers about sexual matters and also to conduct research in the area. The sexual health among Swedish adolescents is often described as good. A majority of the young people in Sweden are content with their sexual life and most of their sexual experiences are described as positive (Häggström-Nordin et al., 2005, Rogala \& Tydén, 2003, Tydén \& Rogala, 2004) but in Sweden as in many other countries, most of the interest and most of the research about the sexuality of adolescents has been concentrated on the possible negative outcomes such as unplanned pregnancies, abortions and sexually transmitted infections.

Finally, the early and open discussion of sexuality in the Swedish society has characterized Sweden (and other Nordic countries) and had set them apart from many other European countries (von Hofer, 2003). Characteristic of conditions in the Nordic countries are a high 
degree of gender equality, diverse family patterns, and rather liberal attitudes to female and adolescent sexuality (Abela et al., 2003; Lewin, 2008; Social Watch, 2013; Vogel, 1998).

\section{Sexual development}

\section{Background to sexual development}

Love and sex are essential to human life and they are extraordinarily variable in the way they are described or expressed. Human beings are sexual beings throughout their entire lives. Human sexual development can be described from different angles. One way is through biological evocation with basic physiology and anatomy, another through social evocation or an interaction between biological mechanisms and socio-cultural factors. Sexuality is most often described as something not at all stable but rather changeable and plastic due to physical and psychological development and also of course due to experiencing different life events. Foucault took a constructionist approach to sexuality describing sexuality as an ever changing social construction and not something made constant by biology (Foucault, 1980). Boys and girls become sexual actors through integration with society, oneself and others. The nature of individual sexuality is not pre-determined by birth. Caplan (1987) describes the fluidity of sexual development in this way: What is sexual in one context may not be so in another: an experience becomes sexual by application of socially learned meanings. Our heads, it has been said, are our most erogenous zone.

The interaction between biology and socio-culture is difficult to study as the socio-culture differs from place to place and from time to time. There have always been certain taboos about sex and in many cultures sex is associated with some degree of shame. In research sex is seen as a sensitive topic at the same time that the western world gets more and more sexualized. One of the pioneers, Alfred Kinsey, claimed in his research that sexual expressions was distorted by socially driven guilt and anxiety and that it fostered problematic and stereotyped relationships between men and women (Gathorne-Hardy, 2000). Fifty years later Hobsbawm observes that the social pressure is not as strong nowadays as it was a half decade ago. He calls it "The triumph of the individual over the society". He states that humans have increasingly been given the chance to make their own individual welfare and personal development top priorities in their lives. He claims that relationships nowadays are 
not the institutions they were earlier, relationships do not develop for official or material reasons and they can be homosexual as well as heterosexual. He employs the concept of the pure relationship, something that lasts as long as both partners are satisfied with the personal bonus the relationship provides and that this affects sexuality in a positive way (Hobsbawm, 1997). Most sexuality research, in common with the research of both Hobsbawms and Kinsey, is focused on adolescents or adults.

Some researchers claim that sexuality and its different expressions by men and women or boys and girls can be explained by the fact that the gender of boys and men is different from the gender of girls and women. Women and girls are usually described as more relation- and intimacy orientated while men and boys are described as more direct and physically orientated in their sexuality (Hulter, 2004, Lewin \& Helmius, 1983). Other researchers discuss gender and sexuality according to the social constructionist theory. For example Kessler \& McKenna (1978) and Berg (2011) describe gender and sexuality as "somethings" we become in the society we live in. Gender is something we do together with others, through our whole life (Kessler \& McKenna, 1978). We are not women and men, we became women and men though interaction with others. It is of great importance with whom and where this interaction takes place (Berg, 2011).

Gagnon and Simon (1973) explain how sexuality and sexual behaviour form by using a model called the script model. They claim that humans learn to follow a certain script (a manuscript) when it comes to sexual behaviours and sexual acts. They describe the script on three levels: social-, group- and individual level.

A social script, is a script formed depending on where and when you live. The norms and culture in the society in a certain time influence the sexual behaviours among the people living there. The script can consist of, for example, certain norms common in the western world that differ from those in the Middle East as concerns sexuality. This affects how people live and act and also what they think is normal, deviant, healthy, unhealthy, acceptable or unacceptable sexual behaviour. The broad social script is expected to capture the norms in the society about sexual practise. A script on the group level points out mechanisms and patterns at that level. The social script affects the members in a certain group. Different groups are for example teenagers, members in a church, well-educated western adults, retired Moslem men etcetera. There are different scripts in different groups and they affect how you show your sexuality. Teenagers, for example, usually behave and dress and show their sexuality in other 
ways than a group of members of a church in their 70s. The personal or individual script depends on your own experience and who you are. Experiences such as abuse, neglect, parental sexuality, attachment style or one's own sexual preferences. How this script is formed during life depends on the social and cultural environment, religion, and personal sexual aspects and on the sexual norms at the time. The child learns a script and that script will develop and be felt more and more personally during the child's development. According to Gagnon and Simon when, where, how and with whom a human being has sex is no coincidence (Berg, 2011; Gagnon \& Simon, 1973).

The most common social script of today is the heterosexual norm with a two-gender model and the monogamous heterosexual relationship (Berg, 2009). At the group level the child and the adolescent learn the script from television, Internet, pornography, teachers, parents and other adults but mostly from their peers (Sorensen, 2007). Some changes in attitudes (which will change the script) have been noticed the past ten years. Lewin et al. and Herlitz describe one change in attitude namely that the "love" ideology is not as strong as it has been earlier (Lewin et al., 1998; Herlitz, 2004). The love ideology represents a belief that sex is a legitimate element of love and romance, especially for women. Sex for fun and for pleasure is taboo while sex in a relationship with romance and love is to be viewed as legitimate (Helmius, 1990). Today it is more acceptable to engage in sex outside a relationship than in times past. The love ideology has been debated and challenged by those who assert that it is more acceptable in the 21 st century to have sex with someone without having a romantic relationship with that person, a practice that has been called "buddy sex" (Lewin et al., 1998). One night stands have also become more common than in the past, and having sex with several partners at the same time is also more common than in the past. In addition there is a more accepting attitude towards homo- and bisexual acts and to the idea that it is ok if the girl or woman initiates the sexual act (Herlitz, 2005). The script adults have today will not be the same for the children of today when they grow up.

\section{Sexual development and attachment}

Of the many different relationships formed over the course of the life span, the relationship between parent and child is among the most important (Steinberg, 2001). Bowlby claims that a loving, responsive, and helpful parent who is always available for his or her child serves the function of binding the child to that parent and contributes to the reciprocal dynamics of that 
binding (Bowlby, 1988). Bowlby also claims that the quality of the relationship between the child and the parent(s) is of great importance for sexual and emotional relationships later in life (Bowlby, 1965). In establishing a primary relationship as adolescent or young adult, individuals bring a history that has shaped their behaviour repertoire and expectancies (Starkes, Newcomb \& Mustanski, 2015).

According to the attachment theory, an individual forms as a child depending on how they attached to their primary caregiver based upon the early interaction between caregiver and infant. The attachment depends on the interaction between the child and the caregiver and how well the caregiver can meet the psychological needs of the child. The child will early seek love, closeness and protection from its caregiver when there is a need for comfort, support and safety. The child should use the caregiver as a safe base and return to the caregiver when needed. An internal model of the self is created (as acceptable/lovable or not) and others (as safe/available/reliable or not) and will colour the relationships established later in life (Bowlby, 1977). A stable and secure attachment between a child and their parent will facilitate stable emotional attachments in adolescence and adulthood (Goldberg, Muir \& Kerr, 1995) and the individual will perceive him/herself as a lovable and acceptable person and others as safe and available. Internal working models in which others are seen unreliable characterize insecure forms of attachment and may also lead to viewing the self as unacceptable or undesirable to others (Bowlby, 1977).

Ainsworth used Bowlby's attachment theory and developed it further by identifying and namig three different attachment styles: secure, anxious-avoidant and anxious-ambivalent (Ainsworth, Blehar, Waters \& Wall, 1978). A fourth style, disorganized attachment, was developed later (Main \& Salomon, 1990).

One way of creating a stable attachment or bond early in life is through positive physical contact and by responding to the child when the child returns to his or her safe base. Disturbances in the attachment process can inhibit and or harm the child (Broberg, 2008) but Furman et al. claim that an adolescent classified as dismissive with its parents can develop a secure relationship later with friends (Furman, Simon, Shaffer \& Bouchey, 2002). 
Attachment theory is a theoretical framework that is particularly relevant to relationships and has also been extended to sexuality research (Mikulincer \& Goodman, 2006). This theory proposes that early interactions with significant others instil expectations and beliefs subsequently shaping cognitions and behaviours with sexual and romantic partners in adulthood (Butzer \& Campbell, 2008; Bowlby, 1969). Scharff assumed that these early attachment bonds are relevant to emotional and sexual expression in relationships. Psychoanalysts and sex therapists have long explained sexual dysfunction within the context of attachment to parents (Scharff, 2010) but empirical research has only recently begun to explore these associations (Stefanou \& McCabe, 2012). It has been proposed that attachment and sexual behaviour are two instinctual systems that are central to human behaviour and that these two systems have a reciprocal relationship (Diamond, Blatt \& Lichtenberg, 2007). Birnbaum (2007) claims that attachment style shapes the way sexual interactions are experienced. A smooth functioning sexual system involves the mutual coordination of both partners' sexual motives and behaviours (Mikulincer \& Shaver, 2003). Davis, Sharver and Vernon describe a difference between attachment anxiety and attachment avoidance. Those with high attachment anxiety are more motivated to use sex as a way to receive closeness and intimacy and those with high attachment avoidance tend to have more casual sex and do not display a need for intimacy and emotional response (Davis, Shaver \& Vernon, 2004). Mikulincer and Shaver also describe dysfunctions of the sexual system associated with the attachment system. They describe two strategies, sexual hyperactivating and sexual deactivating strategy. Sexual hyperactivation can be used by persons with high attachmentanxiety and involves a great deal of effort and attempts to encourage a partner to have sex, placing significant value on the importance of sex within a relationship. These individuals usually have a hypervigilant stance toward perceived sexual rejection. In contrast, sexual deactivation involves inhibition of sexual desire, avoidant attitudes toward sex, distancing from a partner who is interested in sex, and inhibition of sexual arousal. A strategy sometimes used when the attachment style is high of avoidance. (Mikulincer \& Shaver, 2003) Therefore, the attachment and sexual behaviour systems can impact sexual function and dysfunction within romantic relationships (Stefanou \& McCabe, 2012). 


\section{Sexual development during childhood}

How a child becomes a sexual human being and what different factors affect the development of sexuality are subjects of a complex and as yet not very well understood research field. According to the World Health Organization (WHO), sexuality is influenced by the interaction of biological, psychological, social, political, cultural, legal, historical, religious and spiritual factors (WHO, 2006). The process of sexual development starts before the child is born and has an extraordinary intense period during adolescence. WHO (2015) defines adolescence as the period between childhood and adulthood, 10-19 years of age. DeLamater and Friedrich (2002) postulate that the sexual capacity for a sexual response is present from birth and that experiences in childhood can establish preferences for certain kinds of stimulation that persist for life.

The development of an awareness of oneself as male or female, and the value one places on being a member of one's own sex, gender identity, begins early in life. Already at birth the influence begins from hospital staff, parents and friends providing pink or blue clothing, masculine or feminine names and toys and also in the way they speak and treat the child. By the age of 2-3 years most children have developed at least a partial understanding of the concept of gender.

The young child can exhibit a variety of sexual expressions, often increasingly, until the age of 6 to 9 when the child becomes aware of the cultural norms of what to do openly or not (Bancroft, 2003). Sexual behaviours among toddlers and infants (age zero to one) was studied by Galenson (1990) and she found that boys six to eight months and girls eight to eleven months discovered their genitals by touching them. Genital touching became more direct towards the end of the year since the locomotion was sufficient developed. Schuhrke (2000) asked parents to record all manifestations of their child's curiosity about their own and other people's bodies during the second year of life and almost all children showed interest in their own and especially their parents genitals by touching, naming and/or looking at them. A Swedish study, based on parents' reports on preschool children, showed that children between the age of 3 and 6 normally exhibit a wide range of developmentally related sexual behaviours. Sexualized and problematic behaviour were rare in this normative sample. (Larsson \& Svedin, 2001) In early childhood, typically around the age of three, gender identity forms. The child gets a sense of maleness or femaleness at the same time as he or she 
learns the gender norms in the socio-culture they belong to. (Bussey \& Bandura, 1999). They learn how girls and boys, men and women are supposed to be and act in the culture and time they live in. They usually practice this through play and practicing adult roles (playing house). The anatomical differences between males and females are normally also an area of interest in this stage of life as well as the physiology of reproduction. One way of learning about anatomy is playing doctor. In the Swedish study mentioned above, more than $40 \%$ of the children were reported as playing doctor, touching genitals at home, looking at other children's genitals, walking around naked at home, trying to look when other people undress, showing interest in the father's penis and touching the mothers breasts. Earlier studies showed that the most frequently reported sexual behaviour among children, two to five years of age, were to touch own genitals at home and touch mothers or other women's breasts. To look at other nude people were also common. (Friedrich et al., 1998; Larsson \& Svedin, 2002; Lopez Sanchez et al., 2002; Sandfort \& Cohen-Kettenis, 2000; Thigpen, 2009). In three other studies. children between two and five were directly asked about their knowledge of sexuality: for example knowledge of the proper names for genitalia, the differences of boys and girls and reproduction. It showed that they knew about genital differences, gender identity, sexual body parts and nonsexual functions of the genitals. Knowledge about preganancy, birth, reproduction and especially adult sexual behaviour were limited. (Brilleslijper-Kater \& Baartman, 2000; Gordon, Schroeder \& Abrams, 1990; Volbert, 2000)

Larson \& Svedin (2001) showed some gender differences; boys masturbate, touch their genitals at home and in public more often and girls rub their body against people or objects more than boys do. Gender studies show that a large part of boys' gender identification is connected to having a penis and that parents allow them to touch their genitalia more freely and more often appreciate when boys show their genitalia than girls (Bjerrum Nielsen \& Rudberg, 1991).

A child can by accident experience the sensation of touching its genitals in a way that could be described as masturbation, for example when in the shower or by rubbing. Masturbation for a child is not a sexual act. The child has not yet learned to give behaviours like masturbation a sexual meaning. Adults on the other hand will probably give behaviour like that a sexual implication (Helmius, 1990). In that way the parents and society form the sexuality of the children. 
In order to describe common sexual behaviours among preschool children Cavanagh Johnson (1995) listed frequent and expected sexual behaviours among children up to school age:

- touching/rubbing genitals when diapers are changed, when going to bed, when tense, excited or afraid.

- exploring differences between males and females, boys and girls.

- touching one's own genitals, breasts of familiar adults and children.

- taking advantage of the opportunity to look at nude persons.

- asking about the genitals, breasts, intercourse and babies.

- like to be nude. May show others his/her genitals.

- interest in watching people doing bathroom functions.

- playing doctor, interested inspecting others' bodies.

- interest in one's own feces.

- putting something in one's own genitals or rectum due to curiosity or exploration.

- playing house, acting out roles of mum and dad.

\section{Sexual development during preadolescence}

During preadolescence (between 8 to 12 years of age) the child continues to organize females and males into separate groups and usually the exploration and learning involve persons of the same gender. Some behaviours are more typical for middle childhood than for preschoolers, playing doctor, asking questions about sexuality, looking at nude pictures, drawing sexual parts, talking about sex acts and knowledge of sexuality (Friedrich et al., 1998; Sandfort \& Cohen-Kettenis, 2000). About $40 \%$ of the children discover masturbation and report experiencing sexual attraction before puberty, at 10 to 12 years of age (Bancroft, 2003). During this period of life also group dating and or heterosexual parties often occur, which can be the beginning of the process of developing a capacity to sustain intimate relationships (DeLamater \& Friedrich, 2002). Most children have knowledge about sex and sexual intercourse but have not practiced with someone else. Most have some knowledge about contraception and sexually transmitted infections (Finkel \& Finkel, 1981). 
Cavanagh Johnson (1995) describes some common and expected sexual behaviours among preadolescents:

- asking questions about genitals, breasts, intercourse and babies.

- interest in watching/peeking at people doing bathroom functions.

- playing doctor, inspecting others bodies.

- showing others his/her genitals.

- interest in urination and defecation.

- touching one's own genitals when going to sleep, when tense, excited or afraid.

- playing house, may simulate all roles of mum and dad.

- talking about sex with friends. Talking about having a boy/boyfriend.

- looking at nude pictures.

- drawing genitals on human figures.

- exploring differences between males and females.

- taking advantage of looking at nude child or adult.

- pretending to be the opposite sex.

- wanting to compare genitals with friends the same age.

- interest in touching genitals, breasts, and buttocks of children the same age or letting them touch his/hers.

- kissing familiar adults and children. Allowing kisses by familiar adults and children.

\section{Sexual development during adolescence}

Adolescence is a dramatic period of emotional, cognitive, social and biological changes (Patton \& Viner, 2007). Puberty, a signal of the onset of adolescence, normally occur with dramatic biological and physiological changes (Petersen, (1998). The adolescent will experience several types of maturation, including physical and cognitive (the development of formal operational thought).

Physical changes such as an enlargement and maturation of the gonads, genitalia and secondary sex characteristics often start to occur at the age of 10 to 14 years of age and lead to the achievement of fertility (menarche for girls). Normal puberty consists of a series of predictable events, and the sequence of changes in primary and secondary sexual 
characteristics (size of penis, testicular volume, size and shape of breasts, development of pubic hair) has been categorized by several groups, commonly referred to as the Tanner stages I-V.

Stage I is expressed by pre-pubertal development of external genitalia, breasts and pubic hair and stage $\mathrm{V}$ is reached with the development of adult genitalia, breasts and pubic hair (Tanner, 1967). The mean age for menarche in white healthy girls is 12.6 years (Biro et al., 2006) but it can vary from 8 to 17 years and still be considered as normal and not pathological (van den Berg et al., 2006). Sex hormone concentration rises and produces sexual lust and many of the males start to masturbate at the age of 13 to 15 while the onset in females is more gradual (Bancroft, 2003).

Biological factors such as hormonal changes induce puberty and the time of the onset of puberty can predict the time for sexual debut. An early onset of puberty can lead to an early sexual debut. (Landsford et al., 2010) Sex hormones and neuro-transmitters like dopamine and serotonin play an important role in sexual development especially in sexual behavior, sexual arousal and satisfaction (Argiolas \& Melis, 2003). Dopamine has been associated with motivation and reward-related behaviors, with high levels increasing sexual motivation and sexual behavior (Hull, Muschamp \& Sato, 2004) while the release of serotonin has been reported to have an inhibitory influence on sexual behavior and libido (Hull, 2011).

Most adolescents in western cultures start engaging in romantic relationships and sexual activities, including sexual intercourse, during adolescence (Miller \& Benson, 1999) and having a partner has been shown to be positive in some ways. Romantic relationships in middle and late adolescence protect the adolescent from feelings of social anxiety (La Greca \& Harrison, 2005).

Sexual maturation continues through life and one task that many describe as difficult, is learning how to communicate with partners in intimate relationships. There are few role models in society showing us how to do this in an honest, respectful and direct way (DeLamater \& Friedrich, 2002). Another difficult topic is how to be sure to have a partner's consent to start or to continue a sexual act. Ericsson observes that the establishment of intimacy - "the capacity to commit oneself to concrete affiliations which may call for significant sacrifices and compromises" becomes the salient developmental task as individuals emerge from adolescence into young adulthood (Ericsson, 1980). 


\section{Sexual identity}

Sexual orientation matures during adolescence. Sexual orientation can be defined as a multidimensional construct including the three dimensions: sexual identity, sexual attraction and sexual behaviour. Within each dimension, different types of sexual orientations are specified. The most common types are heterosexual, homosexual and bisexual (Lauman, Gagnon, Michael \& Michaels, 1994). For example, one can identify oneself as heterosexual, be attracted to both men and women and have or have not had same-sex or opposite-sex sexual experiences. The same person can have different orientations between the dimensions (Rosario et al, 2006). Researchers should carefully choose which dimensions of sexual orientation and which measures they wish to use (Priebe \& Svedin, 2012). A recent Swedish study used instead four measures of sexual orientation. The researchers used one measure for sexual identity, two for attraction (emotional attraction or romantic attraction) and one for sexual behaviour. Among the representative sample of 3432 high school seniors the prevalence rates of sexual minority orientation varied between $4.3 \%$ for sexual behaviour (males $2.9 \%$, females $5.6 \%$ ) and $29.4 \%$ for emotional or sexual attraction (males $17.7 \%$, females $39.5 \%$ ). Bisexual or homosexual orientation was reported by $1.5 \%$ of the participants in all four measures and by $17.6 \%$ in at least one measure (Priebe \& Svedin, 2012).

Another form of sexual orientation is asexuality. Asexuality or nonsexuality is the lack of sexual attraction to anyone, low or absent interest in sexual activity (Bogaert, 2006; Kelly, 2004). Acceptance of asexuality as a sexual orientation and field of scientific research is still relatively new (Prause \& Graham, 2004; Melby, 2005). According to a study in 2004 the prevalence of asexuality in the British population is 1\% (Bogaert, 2004).

Yet another sexual minority group consists of transpersons. A transperson is an individual who self identifies as a transsexual or transgender (an umbrella term used to describe people whose assigned sex at birth is not fully aligned or congruent with their current gender identity or expression (Reisner et al., 2014), a transvestite (an individual who periodically dresses in the clothes of the opposite sex), transgender (an individual who is living as the opposite sex but does not undergo reassignment treatment), female to male (FtM) or male to female (MtF) 
(reconstructing sex by medical treatment and/or surgery), cross-dresser (an individual who likes to dress as the opposite sex), drag queen (a man who dresses as a woman for fun, show or party), drag king (a woman who dresses as a man for fun, show or party) or boychick (a female transvestite who dresses as a man).

The investigation of youth's sexual orientation is complicated as they might not have passed important milestones in the development of their sexual orientation (Svin-Williams \& Diamond, 2000). They may perceive their sexuality and sexual orientation as more fluid and changing over time (Pedersen \& Kristiansen, 2008; Savin-Williams, 2005).

Being lesbian, gay and bisexual (LGB) has been seen or believed by some researchers as being associated with a lower quality of life as well as a more risky sexual behaviour than heterosexual teens (Mayer et al., 2014).

Russel and Joyner (2001) report that suicidal attempts are more common among lesbian, gay and bisexual adolescents, than among heterosexuals. Because societal discomfort with atypical expressions of sexual orientation, sexual minority groups have enhanced developmental challenges compared to heterosexual youth, which can result in different kinds of health disparities (Mayer KH, Garofalo R \& Makadon HJ, 2014). Furthermore, the suicide attempts among LGB adolescents are found to be positively associated with the parents' negative response to the sexual orientation of the adolescent (Ryan et al., 2009). A Dutch study among 1546 high school students showed that having feelings of same sex attraction predicted lower self esteem and higher levels of psychological distress (Bos et al., 2014). Historically substance abuse problems were thought to be more prevalent among sexual minorities (Bux, 1996; Marshal MP et al., 2013) and recent research also finds an association between bisexual identity and/or behaviour and increased risk of substance abuse (Green \& Feinstein, 2012) and higher smoking prevalence (Grady et al., 2014).

An analysis made by the Swedish Federation for Lesbian, Gay, Bisexual and Transgender Rights (RFSL) in 2015 described factors that can increase the chances of a high quality of life for LGBTs. These factors were for example, living geographically close to other LGBT individuals, access to an infrastructure for LGBTs (e.g. organizations for LGBTs) and the existence of meeting places and or commercial nightlife with LGBTs as target group (RFSLs Kommunundersökning, 2015). Another Swedish study showed that LGBT adolescents often quit their sports due to the common norms in the sport club, the gender division, lack of role models, low LGTB competence and low presence of adults in the sport arenas and 
associations. They also describe a homophobic jargon among trainers and peers and also specific obstacles like having to change or shower in a gender specific dressing room. LGBTs therefore choose individual training that not requires a coach, teammates or dressing rooms (Hbtq och Idrott, 2013). Many homo- and bisexuals feel uncomfortable and unsure when having contact with banks, insurance companies, travel agencies etcetera due to earlier experience of bad treatment because of their sexual identity (Våningssäng på bröllopsresan. En kartläggning av hur bra svenska företag är på att bemöta homo- och bisexuella kunder, 2007). The examples above can be interpreted as a way of being rejected or excluded in society. Humans have a fundamental need to belong and being rejected is painful. Eisernberger et al. (2003) showed in a neuroimaging study that being rejected even in the most simple way, playing Cyberball (a virtual ball-tossing game), in which the participants ultimately were excluded) showed results similar to those from physical pain studies. The anterior cingulate cortex (ACC) is believed to act as a neural "alarm system" or conflict monitor, detecting when an automatic response is inappropriate or in conflict with current goals (Bush, Luu \& Posner, 2000). Earlier research has shown that pain, the most primitive signal that "something is wrong," activates the ACC (Rainville et al., 1997; Sawamoto et al, 2000). Eisenberger et al. (2003) found that ACC was more active during social exclusion (as when experiencing physical pain) than during inclusion and correlated positively with selfreported distress.

\section{Sexual behaviours}

\section{Research on children's sexual behaviour}

Research on children's sexual behaviour has not been extensive partly due to its being a sensitive topic, being made difficult by societal taboos around sexuality and by other obstacles to performing such studies. It is ethically problematic to examine different areas of sexuality and especially children's sexuality and sexual behaviour (Friedrich, 1997). Very few studies have been made by question or observing the children themselves (direct methods) (Brilleslijper-Kater \& Bartman, 2000; Rademakers \& Straver, 2000) so other indirect approaches have been necessary. 
There are three common main routes to studying sexual behaviour among children: 1) to study clinical groups of children brought to clinics because of an adverse sexual behaviour (Gil \& Cavanagh, 1993; Kendall Tacket et al 1993), 2) gathering information retrospectively from adolescents or adults about their sexual behaviours and experiences as children (Finkelhor, 1983; Haugaard, 1996; Lamb \& Coakly, 1993), and 3) gathering information about the child's behaviour from professionals, parents or other caregivers' observations (Friedrich et al., 1991; Friedrich, Fisher et al., 1998; Phipps-Yonas et al, 1993; Larsson \& Svedin, 2001; Lindblad et al., 1995). Friedrich and colleagues developed, from an original questionnaire designed to be given to mothers of sexually abused children, a questionnaire for normative groups of children called the Child Sexual Behaviour Instrument (CSBI) to screen 2-12 year old children's sexual behaviours (Friedrich et al., 1991). The CSBI is still in use by many clinicians and researchers and has been translated into many languages including Swedish. Another way of studying sexuality and sexual behaviour among children has been to make observations in group settings outside the family residence, using family day care providers or preschool staff as reporters (Davies, Glaser \& Kossoff, 2000; Lindblad et al., 1995; Phipps-Yonas et al., 1993). It has been argued that this way of using adults' observations of children's sexual behaviours has been argued to maybe underestimate the extent of exploration, experimentation and sexual activity among the children since they are socialized quite early and learn not to show such behaviours in public (Heiman, Leiblum et al., 1998). Larsson \& Svedin (2001) discuss the limitation of reported behaviour as they do not always represent the true behaviour. Direct observation of children might have produced different results but ethical considerations make it almost impossible to ask young children directly. Observation of children by parents or other caregivers is still an important approach since sexual behaviour that causes concern is, by definition, behaviour that has come to the attention of adults. Observable behaviour is a very important factor to consider when clinicians are to make assessments of a child's developmental status and situation. Knowledge in this area is therefore of great importance.

Studies of normative sexual behaviour, despite differences in methodology, do support the belief that children do engage in a range of overt sexual behaviours. Age seems to be a crucial factor, influencing exactly when and where children, as a result of the socialisation process and knowledge of cultural norms and taboos, learn which behaviours are accepted and which are not (Reynolds, Herbenick \& Bancroft, 2003). 
Most sexual behaviour among children is common and developmentally appropriate but it can be sexualized, violent and abusive. The majority of the sexual behaviours among children do not require intervention but if it is intrusive, hurtful and/or age inappropriate the child may reside or resided in a home characterized by inconsistent parenting, violence, abuse or neglect (Kellogg, 2009). As a consequence of worrisome sexual behaviours much if the research that has been done has been focused on sexual behaviour in normative samples of children in order to find characteristics that may establish the boundaries between 'normal' and 'deviant' sexual behaviour, the latter possibly indicating sexual abuse (Freidrich et al. 1991; Frierich et al. 1992; Friedrich, 1997; Larsson et al 2000; Larsson \& Svedin, 2001). No specific sexual abuse syndrome has yet been confirmed (Paolucci, Genius \& Violato, 2001). Results of earlier research all point to the importance of context in assessing the nature of sexual behaviour in children (Friedrich \& Lane, 2002; Ybarra, Mitchell, Hamburger, Diener-West \& Leaf, 2010).

\section{Common sexual behaviours}

Sexual behaviours or sexual acts are something that can be performed either by a solitary individual masturbation and sexual fantasies are examples - or those that are performed by at least two people. Sexual acts can be divided into non-penetrative and penetrative sex. Penetrative sex includes vaginal, oral and anal sex (Crocett, Rafaelli \& Moilanen, 2003).

Different behaviours are considered as normal in different cultures and in different times. One way to describe normal sexual behaviour in a time or in a culture is to describe the behaviours that are most frequent. For example, in Sweden in the beginning of the 21 st century, the most common among voluntary penetrative sex is vaginal intercourse. The second most common or usual is oral sex and the last is anal sex (Häggström-Nordin, Hansson \& Tydén, 2005, Svedin \& Priebe, 2009). Research from the United States shows the same trends with vaginal intercourse as the most common penetrative sex followed by oral and anal (Martinez, Copen \& Abma, 2011). Most sexual behaviours shown by children are common and of no concern (Larsson \& Svedin, 2001) and are often called normal sexual behaviour. More explicit sexual behaviours such as those that are more like adult sexual behaviours (for example oral or anal sex) are very uncommon among schoolchildren or younger and are often called abnormal behaviours. Children usually discover life with curiosity and joy and common sexual 
behaviour (often called normal sexual behaviour) should be seen as part of that process of discovery as well.

\section{Uncommon sexual behaviours}

An uncommon or an infrequent sexual behaviour can result for many different reasons. An uncommon sexual behaviour does not have to be problematic but some of the uncommon sexual behaviours are. These are absolutely not always a result of sexual abuse but when a child has been sexually misused, abused, or overly exposed to adult sexuality, disruptions in many different areas of the child's sexual development can occur. The child can then sometimes show sexualized behaviours, become prematurely eroticized or overly concerned about his or her gender, have too much knowledge about sex given the child's age or have confused ideas about sexual relationships. A child who has lived in an incestuous home or in a home with poor sexual boundaries may not have been adequately socialized regarding sexuality. (Cavanagh Johnson \& Friend, 1995) Earlier research shows that there is a higher frequency of sexual behaviour in sexually abused children than in non-abused (Deblinger et al., 1989; Finkelhor, 1979; Friedrich, 1991; Friedrich et al., 1992). Friedrich research (1991) indicates that children with a more severe history of sexual abuse (great number of perpetrators and when force or violence was used to perform sexual abuse) showed more sexual behaviours than children whose abuse was not characterized by these features. There is no sexual behaviour in particular that is exclusively engaged in by sexually abused children (Friedrich et al., 1992).

Cavanagh Johnson (1995) lists some of types of children's sexual behaviour that are of concern and should draw attention from adults and professionals:

- the child continues to rub/touch genitals in public after being told several times not to do so or does this to the exclusion of normal childhood activities.

- playing male or female roles in an angry, sad or aggressive manner. The child hates his or her own or others sex.

- touching genitals and breasts of adults not in his or her family or sneakily touching adults. demands to be touched him- or herself.

- asks or tries to force people to undress.

- has too much sexual knowledge for his or her age. 
- wants to be nude in public even after parents have said no or secretly shows self in public after being told not to.

- displays fear or anger about babies, birthing or intercourse.

- forces other children to play doctor or to take off their clothes.

- puts something in his or her own genitals or rectum or of another child after being told not to or uses

coercion or force in putting something in other child.

- having simulated or real intercourse or oral sex with other children.

- telling “dirty jokes” or makes sexual sounds.

- wanting to play games related to sex and sexuality with much younger or older children.

- forcing others to play sexual games.

- draws pictures of sexual intercourse, oral sex or group sex.

- overly familiar with strangers. Talk/act in a sexualized manner.

- sexual behaviour with animals.

\section{Sexual risk behaviours}

The adolescent period is a period with risk-taking behaviour together with a sense of invulnerability. Some researchers even claim that adolescents are not cognitively or emotionally mature enough to the challenges of sex (Reyna \& Farley, 2006) and that minor delinquency seems to be a part of a normative adolescence (Rutter \& Giller, 1984). Some examples of sexual risk taking behaviours often reported are; early age at first intercourse, unprotected sexual activity, high numbers of sexual partners and selling sex (HäggströmNordin, Hansson \& Tydén, 2002; Tydén et al., 2012). According to Swedish research there has been an increase in risk-taking sexual behaviour among adolescents (Tydén at al., 2012). Some youths are at greater risk than others. Adolescents in psychiatric care, for example, engage in higher rates of sexual risk-taking than their same-age peers (Brown et al., 1997; Donenberg et al., 2001); they initiate sex at earlier ages and report high rates of sex without a condom, sex while using drugs and alcohol, and sex with multiple partners (Donenberg et al., 2001, 2002).

Internet has become an arena for all kinds of sexual activity and the increased access to the Internet has increased the opportunities for sexual risk experiences and behaviours such as, 
for example, receiving unwanted sexual material or unwanted sexual approaches, consuming pornography, sharing nude pictures online, being groomed, harassed or exploited online. Baumgartner et al. (2010; 2012) defined online sexual risk behaviour as the exchange of intimate sexually insinuating information or material with someone exclusively known online. The authors gave examples of four behaviours: searching online for someone to talk about sex to, searching online for someone to have sex with, sending intimate photos or videos online, disclosing personal information like telephone numbers and addresses to someone online.

To sell sex is also a risk behaviour and has been associated with a more sexualized behaviour in general (Svedin \& Priebe, 2014). There has been an increase in selling sex among adolescents (Fredlund et al., 2013) maybe because it has become easier since the marketplace for selling sex has shifted the arena from being the street to the online world (Cunnigham \& Kendall, 2011; Priebe \& Svedin, 2012). A recent Swedish study found that $1.5 \%$ in a normal sample of 18-year olds had at some time sold sexual services (Svensson et al., 2013) and the reported prevalence from other western countries is of this magnitude (Helweg-Larsen, 2003; Lavoie et al., 2010; Pedersen \& Hegna, 2003). Sexual risk behaviours have been shown to be associated with other risk behaviours such as externalizing behaviour problems, antisocial behaviours and substance use (Tubman, 1996) and selling sex among youth has been associated with alcohol and drug use and also antisocial behaviour (Svedin \& Priebe, 2004, 2009).

\section{The sexual debut}

When the sexual debut and the timing of the sexual debut are mentioned in the literature the focus is usually on early sex debut and on the risks and negative outcomes such as unplanned pregnancies and sexually transmitted infections. The legal debut age in Sweden is 15 years and the gender differences are no longer as great as they once were. Women born 1922-1930 had an average debut age for their first intercourse at 19 years of age compared to 18 years for the men (Häggström-Nordin, 2009). The debut age has declined since then and in 1996 the debut age was 16.5 years for women and 16.8 years for men (Lewin et al., 1998). The reason for the decline in debut age is probably multidimensional and several surveys from Sweden and other countries show the same trend (Teitler, 2002; Tikkanen, Abelsson \& Forsberg, 2009; Tydén \& Rogala, 2004; Tydén, Palmqvist, Larsson, 2012). Early-developing girls move faster into romantic relationships, often with older men, and also begin sexual activities 
sooner than do other girls (Compian, Gowen \& Hayward, 2004). Girls generally have an earlier onset of puberty than boys, and the onset of puberty correlates positively with early sexual debut (Downing, Bellis, 2009; De Genna, Larkby \& Cornelius, 2011). Approximately $7.1 \%$ of American youth report sexual debut prior to 13 years of age, with more male than female youths reporting early sexual debut, (Eaton et al., 2008). By the age of 16 years approximately $30 \%$ of the females and $34 \%$ of the males have had sexual intercourse. Some research indicates that an early sexual debut can be predicted even in early childhood, as researchers see a relationship between antisocial behaviour in children between five to eleven years of age and early sexual debut (Ramrakha et al., 2007). Swedish research shows a difference in debut age both in relation to gender and to the educational program. Girls in practical educational programs had the earliest sexual debut while boys in theoretical programs had the latest (Edgardh, Lewin \& Nilsson, 1999). Johansson \& Ritzén (2005) also show a connection between early menarche, early sexual debut and lower level of academic education later in life.

Early sexual debut is often described as a risk factor associated with risk behaviours such as alcohol-, drug abuse and antisocial behaviour (Cornelius, Clark, Reynolds, Kirisci, \& Tarter, 2007). Earlier research show that low parental education and income as well as deficient social support have a positive association with an early debut (Valle, Roysamb, Sundby, \& Klepp, 2009). A Swedish long-term study showed a connection between early menarche and early sexual debut since girls age 15 to 16 with a menarche before age 11 were more normbreaking, were more likely to acquire socially more advanced behaviours at an earlier age and had earlier advanced sexual experiences (Johansson \& Ritzén, 2005). Earlier research also shows that an early onset of puberty and early maturation predict early sexual debut and more frequent unprotected sex as do early introduction to alcohol and being drunk as well as for boys more aggressive behaviour and for girls being absent from school and experiences of being bullied (Belsky et al., 2010; Downing \& Bellis, 2009)

Other studies indicate that exposure to pornography and sexual content in movies is associated with an early sexual debut (O’Hara, Gibbons, Gerrard, Li, \& Sargent, 2012). Pedersen and Skrondal (1996) claim that girls who experienced sexual abuse in early adolescence reported a high number of partners and an early sexual debut. 
Precursors and consequences of a late sex debut is an understudied area but Tolman and McCleeland discuss if "virginity" that is remaining a virgin should be considered a sexual behaviour (Tolman \& McCleeland, 2011). Sandfort et al. (2008) analysed data from the 1996 National Health Survey, a cross-sectional population study of adult Americans. They found that people who postponed their first sexual experience were less likely to have risky sexual partners or have sex under the influence of alcohol and drugs.

An American study including males and females age 15-21 showed that those who viewed religion as very important, had frequent church attendance, and held religious attitudes were less likely to have had their sexual debut and had significantly fewer partners (Haglund \& Fehring, 2010). Religiosity has a protective association with sexual activity and number of partners (Edwards et al., 2011) but both late and early sexual debut were associated with sexual problems such as problems with arousal and orgasm among men compared to men with a normative sexual debut age (Sandfort et al., 2008).

Lammers et al. found a significant association between postponing the onset of sexual intercourse and living in dual-parent families, residing in rural areas, higher school performance, concerns about the community and higher religiosity (Lammers et al., 2000). A late debut or postponing the debut until marriage is often argued as being wise but there is little research on this belief. Sandfort et al. (2009) found though that those who postponed sexual initiation were less likely to have sexual risk partners or to have sex under the influence of alcohol and drugs, but Donders et al. (2011) found a strong correlation between late sexual debut and the necessity to interrupt intercourse due to central introital pain. Women with central introital dyspareunia had their sexual debut at a greater age than otherwise comparable women. Harden (2011) points out that a late sexual debut (in this study, 19 years or older) is associated with decreased odds of marriage or non-marital cohabitation and fewer romantic partners as an adult but is also associated with significantly reduced levels of relationship dissatisfaction if they do get married or cohabitate with a partner.

Biological factors can of course affect sexual behaviours; for example different medications or neurotransmitter levels can induce lust and/or sexual functioning (Argiolas \& Melis, 2003; Cascade, Kalali \& Kennedy, 2009). A well-known side effect of antidepressant selective serotonin reuptake inhibitors (SSRIs) is the decrease of both sexual desire and sexual 
functioning (Cascade, Kalali AH \& Kennedy, 2009). SSRIs can therefore affect sexual behaviours and perhaps even the sexual debut. Since the neurotransmitter dopamine is associated with reward-related behaviors (Hull, 2004) which can include sexual behaviors, one possible theory could be that the adolescents who had not made their sexual debut had low levels of dopamine or that they had not yet experienced the chemical rewards of sexual activity.

When studying sexual debut age it is important to consider that eventual exaggerating or denying sexual debut can impact the results from these kinds of studies. Females tend to underreport their sexual involvement while some males overstate their sexual behaviours (Siegel, Aten \& Roghmann, 1998).

\section{Sexuality and the online culture}

Almost all western adolescents have access to the Internet (Ofcom, 2014; PEW Research Centre, 2013; Statens medieråd, 2013) and the daily use of the Internet among Swedish 13-16 year olds has increased from $62 \%$ in 2010 to $93 \%$ in 2013. Also when it comes to access to mobile phones most youth have their own device (Statens medieråd, 2013). Most popular online activities are related to communication with others, showing that adolescents not are only passive consumers of the Internet but are rather active agents (Statens Medieråd, 2013; Jonsson, 2015). The differences between being online and offline is for most adolescents not a clear line and most can't relate to a life without the Internet. Since they were born in an era of electronic multi-tasking they can be seen as digital natives, compared to persons born before 1980 who can be considered digital immigrants (Palfrey \& Grasser, 2008; Prensky, 2001).

Since life online and offline today are integrated, sexuality has an arena online. Both adolescents and adults use the Internet for sexual purposes (Daneback \& Månsson, 2009; Döring, 2009; Jonsson, Priebe, Bladh \& Svedin, 2014; Jonsson, Bladh, Priebe \& Svedin, 2015; Svedin \& Priebe, 2009). The term online sexual activity refers to Internet use for any activity that involves sexuality for the purposes of recreation, entertainment, exploration, support, education, commerce and/or seeking for romantic or sexual partners (Cooper \& Griffin-Shelly, 2002). This includes activities where adolescents are passive consumers, such 
as e.g. pornography consumption but also activities where they take an active part (e.g. making contact for sexual purposes or sending sexual messages in text or by pictures).

The Internet opens up endless possibilities to seek information about sex. According to some research, young people prefer getting information online over getting it at school or from peers, partners or parents (Jones \& Biddlecom, 2011; Suzuki \& Calzo, 2004) and this has been of great importance for youth of sexual minorities. They have reported feeling less isolated and able more easily to cope with stress and the potential stigma associated with their orientation (Mustanski, Lyons \& Garcia, 2011).

Sending sexual messages ("sexting") in text, pictures and films is one of the best studied online sexual behaviours among youth. In a Swedish study by Jonsson et al. (2015) one fifth of Swedish youth had, in a romantic relationship, either flashed in webcam/mobile (14.4\%), posted partially undressed pictures/films (9.8\%), masturbated on webcam (5.4\%) or had sex with someone on webcam (2.2\%). Sexting has been shown to be associated with other sexual activities. Sexters seem to be more sexually active (Rice et al., 2014; Sorbring et al., 2014) and became sexually active earlier in life (Perkins et al., 2014; Rice et al., 2014). However, sending sexual messages does not necessarily need to be associated with sex. In the report from the EU project SPIRTO (Jonsson, Cooper, Quayle, Svedin \& Hervy, 2015) interviews were conducted with 51 youth in UK and Sweden. The motivations described for sending nude images (where breasts, genitals or bottoms were shown) were to be seen as fun, flirty and a way to meet new people, explore sexuality, and even a way of seeking affirmation, social acceptance/because others are doing it, being part of romantic or sexual relationship, being asked for or in coercive situations.

Sex online can be positive and fun and can offer possibilities to meet new people and experiment with sexuality. On the other hand it can be seen as a risk taking behaviour that can lead to negative outcomes. For example pornography consumption can on the one hand be exciting and fun but on the other hand can develop unrealistic sexual values and beliefs (Eric et al., 2012). Mattebo (2013) showed, in a Swedish study among 477 boys at 16 years of age, that the frequent users of pornography reported more sexual experience, spent more time at the computer and reported an unhealthier lifestyle than average and non-frequent users. One third of the frequent users watched more pornography than they wanted to and obesity was twice as common among the frequent users. In a study by Ybarra et al., (2007) the authors did 
not find a specific online sexual behaviour that was more risky than others, but stressed that youth with a combination of different sexual behaviours online might be more at risk than others. Also in the study by Jonsson et al., 2015 different online sexual behaviours were studied in relation to differences in the social background of the youth. The authors found that youth with a sexual behaviour online had poorer health, lived a more sexualised life and had more experiences of maltreatment along with a more risk taking life in general. Among the studied behaviours few differences were found except for the group of youth who had sold sex online who had a much poorer health, more experiences of maltreatment including physical and sexual abuse, such as meeting a person online for sex online or offline or experiences of sending nude images showed few differences between each other. On the other hand one studied behaviour, selling sex online, stood out and was associated with a poorer health, a more risk taking life in general and more experiences of maltreatment including physical and sexual abuse.

\section{Child Sexual abuse}

Child sexual abuse (CSA) is an old and global problem. It is a criminal act in most societies but research shows that 1 in 15 adults has experienced forced sexual intercourse as a child (Basile et al., 2007). One of the most common definitions of CSA is that published in 1976 by Schechter and Roberge and reads; "Sexual abuse is defined as the involvement of dependent, developmentally immature children and adolescents in sexual activities they do not truly comprehend to which they are unable to give informed consent, or that violate the social taboos of family roles" (Schechter \& Roberge, 1976).

CSA occurs at all ages, in all anatomical ways, in all ethnic groups and cultures and social classes. In a meta- analysis of 217 international publications $12.7 \%$ of all children $(18.0 \%$ of the girls and $7.6 \%$ of the boys) had experience of sexual abuse (Stoltenborgh et al., 2011). In Sweden $10-13 \%$ of the girls and 3-5\% of the boys, at the age of 18 years, has experience of penetrative sexual abuse (oral, anal and vaginal sex) (Priebe \& Svedin, 2009; Svedin \& Priebe 2009). 
According to the Swedish law, all forms of sexual acts against children and adolescents under 18 within the family or by someone who has responsibility for the care/education or a similar relationship to the child are punishable by law. Acts of a sexual meaning directed at children under 15 are punishable irrespective of who utilizes the child (Brottsbalken, chapter 6).

An adult using his or her status to violate the privacy of the child is engaging in sexual abuse and this is an act undoubtedly based on the adult's needs. The abuse does not always physically hurt the child. It can be both of physical or non-physical nature. Examples of physical sexual abuse are vaginal, anal or oral intercourse, the perpetrator masturbating between the thighs of the child, the perpetrator touching the child's genitals or forcing the child to touch their genitals. The child may be awake or asleep or sometimes seduced by drugs. Children and adolescents also occur in connection with prostitution. Sometimes violence is used sometimes not. Violence can be included as part of the assault or as a way to get the child to agree to the sexual act. The perpetrator can also bribe or threaten the child in order to force the child to actions or to not tell anyone.

As with physical abuse it is easier to forget or to not discover the abused children in "wellbehaved" families (families who live in nice areas, parents with education and a stable family economy).

Examples of non-physical sexual abuse include making a child witness sexual acts or pornography, making them show themselves naked, and being filmed or photographed, consciously or unconsciously, without clothes on.

Approximately two thirds of the children show symptoms after being abused (KendallTackett \& Finkelhor, 1993). There is no general abuse syndrome but some common symptoms after abuse are nightmares, intrusive memories (so-called flashbacks), concentration difficulties, depression, substance abuse, insomnia, agitation, anxiety, selfharm, eating disorders, and so on (Cohen et al. 2006). There is research showing a connection between sexual abuse and lifetime diagnosis of psychiatric and/or somatic disorders. Psychiatric disorders include anxiety disorder, eating disorders, posttraumatic stress disorder, sleep disorders and suicide attempts (Chen et al., 2010) and somatic disorders include functional gastrointestinal disorders and chronic pelvic pain (Paras et al., 2009). However, it is important to remember that all the symptoms are not visible and that not all abused children have symptoms. 
It is rare to find marks or signs on the body as a result of sexual abuse. The assault usually results in only small-scale not so readily evident physical damage, but there are some signs on the body that physicians and nurses should be familiar with. Burn marks, bite marks or hickeys on your chest, genital, inner thighs or buttocks can be a sign of sexual abuse. Petechiae on the hard palate in the mouth and small crescent shaped marks in the scalp behind the ears (marks from the perpetrator nails) can be a result of forced oral penetration.

Research shows that children with experience of CSA have difficulty telling adults about the abuse when it is ongoing and even later in life (Devoe \& Faller, 1999). The main reason is probably that talking about the abuse arouses strong emotions, primarily shame and guilt, and that those feelings are difficult for the child to deal with (Leander et al, 2007; Svedin \& Back, 2003).

Abused children do more often seek medical help for different reasons and they do more often have contact with child and adolescent psychiatry clinics than non-abused children (Sakso \& Almroth, 2015) so one way to find these children is to educate care professionals to ask children about different kinds of abuse. 


\section{EMPIRICAL STUDIES}

\section{Aims}

\section{Study 1}

To elucidate sexual behaviour in children between the ages of 7 and 13 as observed by their parents in order to provide a better basis for determining which sexual behaviours are common and which are uncommon in boys and girls.

\section{Study II}

To investigate the relationship between sexual debut before 14-years-of-age and sociodemographics, sexual experience, health, experience of child abuse and behaviour at 18years-of-age.

\section{Study III}

To explore how students who had not initiated sexual activities - voluntary vaginal, oral or anal sex - by the age of 18 differ from those who had made their sexual debut before 18 years of age. Investigating factors such as socio-demographic background, sexual behavior, physical and psychological health, health behavior, self-esteem, sense of coherence and experience of child sexual and, or, physical abuse.

\section{Study IV}

To investigate the relationship between sexual identity and family socio-demographics, sexual experience, health, experience of child abuse, sexual exploitation and present behaviour among Swedish adolescents and young adults. 


\section{Methods}

\section{Study I}

\section{Procedure and participants}

During the study period 2003-2004, 13,290 children attended primary schools in the middlesized Swedish community that was selected. Six primary schools were chosen according to size and the community area where they were situated in order to get a socio-economic spread. The school authorities and thereafter the headmasters of each school gave us permission to approach the teachers in the selected classes and give information about the study. Those who agreed to include their classes were given further information on the procedures, which included letters to the parents sent from the researchers. Parents first received a letter saying that the study was underway and that a questionnaire about their child would be sent to them shortly. Together with the questionnaire a second letter with the background and aim of the study was sent. The parents were asked to return the answered questionnaires in the enclosed pre-addressed envelope. The school saw to it that one reminder from the research team was sent.

\section{Participants}

The study group consisted of 418 children, 210 boys and 208 girls between the ages of 7 to 13. The response rate was $63.1 \%$. The mean age was 10.4 years $(\mathrm{SD}=1.8), 42.9 \%$ were firstborn and the majority of the children, $98 \%$, were born in Sweden $(94.4 \%$ of citizens Sweden 2004, SCB). The vast majority of both mothers $(91.8 \%)$ and fathers $(91.1 \%)$ were born in Sweden. Most of the children, 73.6\%, lived with both biological parents, which corresponds with national data for this age group in Sweden (70.6\% of children aged 7-13 ears of age live with both biological parents 2004, SCB). Of the participating children were $96.8 \%$ reported fully healthy while $3.1 \%$ were reported mentally retarded and $4.7 \%$ physically disabled.

\section{Measures}

The first part of the questionnaire consisted of a demographic section, the second part on the mental health of the child and the third and last part about the child's sexual behaviours. 
The demographic section consisted of questions about the child and the family-situation (age, gender, child's and parents national origin, number of siblings and the health of the child), socio-economic status (parental relationship, age, education, and employment) and life events (new sibling, change of living conditions, mother or father been sick and in hospital, mother or father recently unemployed, child injured or in hospital, death in the family or close to family, change of home or school, change in child's friend relationships).

\section{Strength and Difficulties Questionnaire (SDQ)}

To measure the mental health or the strengths and difficulties of the child the widely used Strength and Difficulties Questionnaire (SDQ) was used. SDQ is a brief behavioural screening questionnaire for 3 to 16 year olds consisting of 25 items on psychological attributes, both positive and negative (www.sdqinfo.com). The items are divided between 5 scales; emotional symptoms, conduct problems, hyperactivity, inattention and prosocial behaviour (Smedje et al., 1999). The parent or caregiver answers the questionnaire and decides between three options to each of the 25 statements. The options are: do not agree, partly agree, do agree. The internal consistency and validity as well as the sensitivity and specificity for the form have been well tested and found to be good (Goodman, 2001).

\section{Questions about sexual behaviour}

The third part of the battery of questions consisted of a sex behaviour inventory section. Questions from Friedrich's Child Sexual Behaviour Inventory (CSBI) (Freidrich, 1997) were used together with questions in the same area, developed for earlier Swedish studies (Larsson \& Svedin, 2001; Larsson \& Svedin, 2002) and revised for this study. CSBI was developed to assess children who have been sexually abused or are suspected of having been sexually abused. It has questions on nine different domains such as boundary problems, exhibitionism, gender role behaviour, self-stimulation, sexual anxiety, sexual interest, sexual intrusiveness, sexual knowledge and voyeuristic behaviour. CSBI has demonstrated adequate reliability and validity (Friedrich, 1997) as well as sensitivity and clinical utility. Friedrich also showed that sexual abuse characteristics were related to the total score for the child. In this study we only used the CSBI questions as a basis for frequency calculations of different behaviours aged 713 and not as a scale with subscales. The rationale for this was the creation of a battery of questions suitable for this age group and questions such as does your child ask you questions about sex, does your child use sex-words and has your child sexually harassed other children, does your child watch pornographic movies or magazines and several questions about family 
habits like co-bathing, co-sleeping, were added. We excluded some of the CSBI questions i.e. does your child touch animals' body parts and does your child try to undress adults. The parents were asked to rate the frequency of different sexual behaviours seen in the child during the six last months. The rates ranged from $1=$ never, $2=$ less than once a month, $3=$ 1-3 times a month, $4=$ at least once a week and $5=$ often/daily. After analysing the answers in the first phase of the study the research team found that some questions needed to be rephrased, some were omitted and some new questions were added in order to enhance the potential of information, which could be gained from the questionnaire. The parents were also given the opportunity to give a short commentary for each observed behaviour.

\section{Analysis}

Differences between groups were analysed with a non-parametric test, Mann-Whitney U-test and Spearman rho was used for correlations. All statistical analyses were performed using SPSS 19.0 software package for Windows (SPSS, Inc, Chicago, IL). In the analyses of age, the children were grouped in a younger group of 7-10 years of age and an older group of 1113 years of age.

\section{Study II-IV}

\section{Procedure and participants}

During 2009 the study "Youth, sex and the internet" on behalf of The Swedish National Board for Youth Affairs and the Swedish Government was initiated. The data collection was done by Statistics Sweden. The sampling frame consisted of all students in the second grade of a three-year programme in high schools with at least 10 students registered in the Swedish National School Records in autumn 2007. A cluster sampling was used according to the size of the school. The first stratum consisted of high schools with 10-190 students, the second stratum 191-360 students and the third stratum high schools with more than 360 students. 150 of the schools and from each of them were one to two educational programmes selected. This made a complete study group of 7,700 students. The number of participating schools was 119 (31 did not respond to the request for participation or did not return the questionnaires) with 5,792 students. Statistics Sweden distributed the questionnaires to the participating schools during the period of January to April 2009. 
Information letters and later the questionnaires were sent by mail to the principal and teachers of each participating school. The students received written information about the study and gave informed consent by choosing to answer the questionnaire. Parental consent was not needed according to the Swedish Act concerning the Ethical Review of Research Involving Humans as the students were more than 15 years old. The anonymous pen and paper questionnaire was distributed by school staff and completed in the classroom during school hours. The schools sent the completed questionnaires to Statistics Sweden. The adolescents were given information were they could turn for counselling in case of need of support.

\section{Participants}

In total, 3,503 students answered the questionnaires (response rate 60.5\%). 71 questionnaires were excluded, five because the answers were not seen as being serious and 66 because the participants did not answer the question about gender or felt unsure about their gender. The schools and the students who did not participate did not skew the material in any direction. The only difference was that $22 \%$ of the sample had an immigrant background compared to $19 \%$ in the total population in Sweden (Statistics Sweden).

\section{Study II}

The sample used in study II consisted of 3,432 students (response rate=59.2\%) 1,594 $(46.4 \%)$ male and 1,838 (53.6\%) female students with mean age of $18.3 \pm 0.6$ years. In total 2,469 (71. $8 \%$ ) had had their sexual debut and 963 (28.2\%) had not. Among the 2469 students with a sexual debut 258 of them had it before the age of 14, (the index group) and 2,211 of them had their debut at 14 years or older (the comparison group). The mean age for sexual debut was 15.4 years. (Figure 1 )

\section{Study III}

The sample in study III consisted of 3380 students, the same material as in study II but another 52 were excluded as they did not answer the index question that asked if they had had voluntary vaginal, oral or anal intercourse. Among the sample 830 (24.6\%) students reported that they had not had their sexual debut yet i.e.no vaginal, oral or anal sex. These students constituted the index group, which was compared with students who reported experience of voluntary sex as above (comparison group, $\mathrm{n}=2550$ ). (Figure 1) 


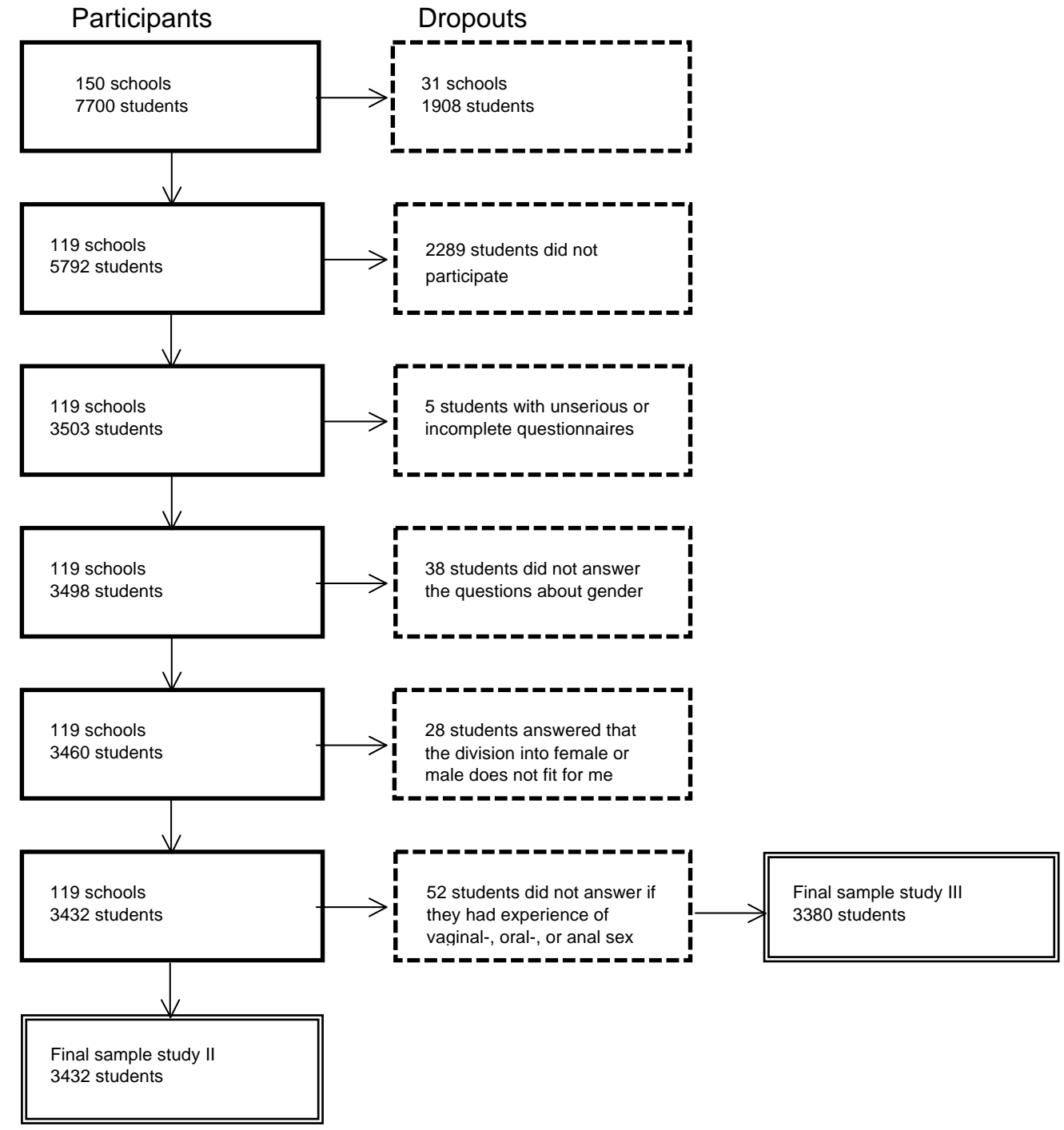

Figure 1. Flowchart showing participants in study II and study III 


\section{Study IV}

The same questionnaire and material were used in study IV (here called the school sample) but also 362 members of the Swedish Federation for Lesbian, Gay, Bisexual and Transgender Rights (RFSL) (called the member sample) completed the same questionnaire. The index question in study IV was whether the adolescents or young adults defined themselves as heterosexual, homosexual, bisexual, unsure or none of the above.

In the school sample the school sexual minority group comprised 346 students who answered homosexual, bisexual, not sure or none of the above and the school heterosexual group comprised 3,107 students. There were 45 participants who did not answer the question on sexual identity. (Figure 2) The mean age in the school sexual minority group was $18.4 \pm 0.7$ years and in the school heterosexual group it was $18.2 \pm 0.6$ years. (Figure 2)

The member sample originated from members of the RFSL who were 18 to 25 years of age and born between 1984 and 1991. The staff at the RFSL office in Stockholm had addresses for all members in the age range and distributed the questionnaire, together with information letters from both the RFSL and the researchers in February 2009. A pre-stamped envelope addressed the researchers was also included so that they could return the anonymous pen and paper questionnaire. The number of members in the age range at the time of the survey was 687 and $364(53 \%)$ with a mean age of $21.4 \pm 2.0$ years returned the questionnaire. The inclusion criterion was that they needed to define themselves as homosexual, bisexual, unsure or none of these. Two of the members did not answer the question about gender, 24 of the participants identified themselves as heterosexual and nine did not specify what group they identified with. Thus, the final sample consisted of 329 participants. A drop-out analysis was carried out, comparing the background data of all the members born between 1984 and 1991 with the background data on the members who answered the questionnaire. Gender could not be analyzed as only $20 \%$ of all the members had given that information to RFSL. The member sample dominated by women $(60.8 \%)$ and the remainder was men $(32.5 \%)$ or members who claimed that the division into male of female did not fit them (6.7\%). The mean age of the participants (21.4 years) was slightly older than the mean age of all the members in the same age range (22.1 years). Just under a quarter (24\%) of the RFSL members lived in a big city or its suburbs while $30 \%$ of the study participants did, meaning that they were overrepresented in the study material and could not be representative for all sexual minorities 
in Sweden. In addition, RFSL members were probably more active and more aware of questions and problems in the field of sexual minorities than non-members. The RFSL member group and the sexual minority school group formed the final index group and are compared throughout this paper with the comparison group of heterosexual adolescents from the school group. (Figure 2)

362 members of RFSL with sexual identity as homo-, or bisexual,

"the member sample"

\section{Participants}

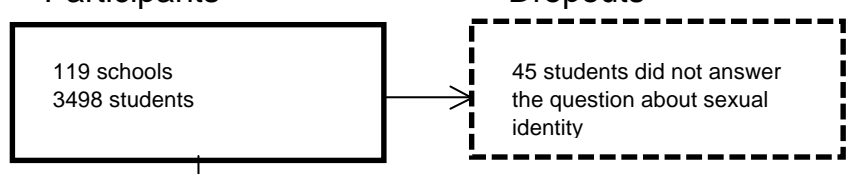

119 schools

3453 students identification as homo-, or bisexual,

"the school sample"
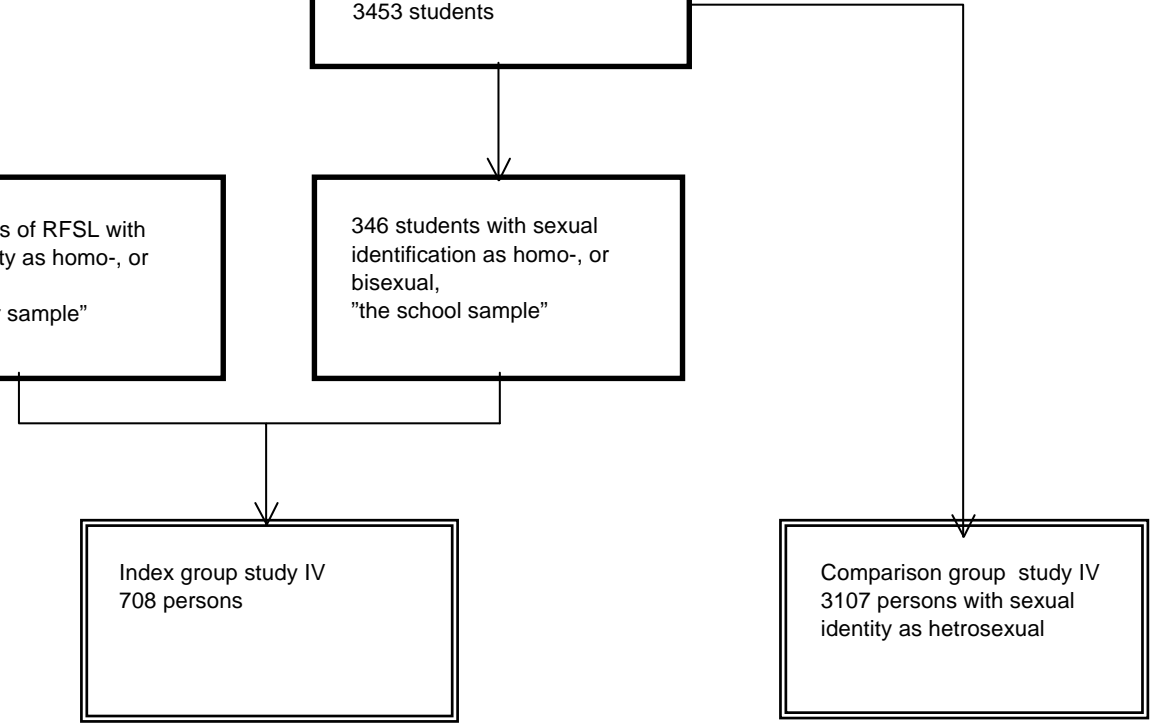

Figure 2: Flowchart showing participants in study IV 


\section{Measures study II-IV}

A study-specific questionnaire consisting of 88 questions, many of them with follow-up questions making the total number of questions approximately 500, was developed. It included five standardized instruments to measure factors such as physical and psychological symptoms (Symptoms Checklist 25), self-esteem (The Rosenberg Self-esteem Scale), sense of coherence (The Sense of Coherence Scale), parental bonding (The Parental Bonding Instrument) and rape myth acceptance (The Illinois Rape Myth Acceptance Scale). The questions were divided into four categories: (1) Socio-demographic data and background, meaning gender (male, female or the division does not suit me), sexual identity (heterosexual, homosexual, bisexual, unsure or none of these) the adolescent's living situation (living with parents or not), study program (theoretical, practical or individual) and immigrant status (born in Sweden or not) parental employment divided into active or inactive. Active was defined as having a job, parental leave or studies and inactive as being unemployed or a pensioner. (2) Love and consensual sexual experience measured by for example sexual identification (heterosexual, homosexual, bisexual, unsure or none of these) There was also a question about identification as a transperson or not. This means individuals who identify themselves as a transsexual (an individual who identifies with the opposite sex and wants to live a life as a member of the opposite sex and sometimes undergo reassignment treatment), a transvestite (an individual who periodically dresses in the clothes as the opposite sex), transgender (an individual who is living as the opposite sex but does not undergo reassignment treatment), Female to male (FtM) or male to female (MtF) (changing sex by medical treatment and/or surgery), cross-dresser (an individual who likes to dress as the opposite sex), drag queen (a man who dresses as a woman for fun, show or party), drag king (a woman who dresses as a man for fun, show or party) or boychick (a female transvestite who dresses as a man). In the member questionnaire there was a following question asking if one described oneself as a transperson could the adolescent specify what type of transperson he or she was (transsexual, transvestite, transgenderist, MtF, FtM, cross-dresser, drag queen, drag king or boychick. Sexual experience of sex with a person of the same sex and opposite sex (oral, anal or vaginal sex) was also asked for as well as age at first time experience of sexual intercourse, number of sexual intercourse partners (none, 1, 2-5, 6 or more partners). Also use of pornography was measured by a question "if ever watched pornography" (images or movies where one or more people are having sex with themselves or each other. (3) Health and health behaviour, 
measuring the use of cigarettes, alcohol and other drugs and different kinds of antisocial behaviours such as "ever been away from home without parents' knowledge, been in a fight or hurt someone, hit or hurt animal, violent with teacher or threaten or bullied someone". (4) Sexual abuse, sexual exploitation and physical abuse experience. Sexual abuse was measured by a question "if the adolescent ever experienced sexual abuse (defined as if someone against one's will had touched genitals or breasts, tried to undress to have sex or if the adolescent had to masturbate, have vaginal, oral or anal sex". To measure sexual exploitation there was a question "if the adolescent ever had sold sexual services. Physical abuse by adult was measured by questions "if ever having experience of being pushed or shaken by adult, if an adult ever threw something at them, hit them by hand, kicked, hit with fist, bitten, hit with object or burnt or scalded".

\section{Symptoms Checklist 25 (SCL-25)}

SCL-25 was developed from SCL-90 (Derogatis, 1977) and measures occurrence of psychiatric symptoms, mainly depression and anxiety, during the previous week. The measure consists of 25 items with a 4-point scale ranging from $1=$ Not at all to $4=$ Extremely. A total score ranging from 25 to 100 is calculated, with high values indicating a high symptom score. A cut-off was set at the 80th percentile with values $\geq 57$ indicating poor mental health in the member material and $\geq 53$ in the school material. SCL-25 has been shown to have acceptable reliability and validity (Nettelbladt et al., 1993; Strand et al., 2003). Cronbach's alpha was 0.93 in the school sample as well as in the member sample.

\section{The Rosenberg Self-esteem Scale}

The Rosenberg Self-Esteem Scale (Rosenberg, 1998) consists of 10 questions on current experience of self-esteem, ranging from $0=$ Strongly disagree to $3=$ Strongly agree. The total score ranges from 0 to 30 with high values indicating high self-esteem. A cut-off was set at the $20^{\text {th }}$ percentile with values $\leq 14$ indicating low self-esteem for the member material and $\leq 16$ for the school material. Cronbach's alpha was 0.89 in the school sample and 0.91 in the member sample.

\section{The Sense of Coherence Scale (SOC)}

The Sense of Coherence scale (SOC) measures the individual's current sense of coherence 
which expresses the extent to which one has a pervasive, enduring though dynamic feeling of confidence that (1) the stimuli deriving from one's internal and external environments in the course of living are structured, predictable, and explicable (comprehensibility); (2) the resources are available to one to meet the demands posed by these stimuli (manageability); and (3) these demands are challenges, worthy of investment and engagement (meaningfulness) (Antonovsky, 1987). The SOC has been used in a number of previous studies and has been shown to be valid and reliable (Eriksson \& Lindström, 2005). High values indicate a strong sense of coherence. Antonovsky suggested that scores can be collapsed into quintiles or tertiles (Hansson \& Cederblad, 1995). In this study, a weak sense of coherence was defined as values in the lowest quartile with a score of $\leq 46$ in the member material and $\leq 50$ in the school material. Cronbach's alpha was 0.86 in the school sample and 0.87 in the member sample..

\section{Parental bonding (PBI)}

The Parental Bonding Instrument (PBI), developed by Parker et al (Parker, 1983), is a selfreport measure of fundamental parental styles and parental characteristics measured on two scales termed 'care' and 'overprotection' or 'control' as perceived by the child. The measure is retrospective, meaning that persons over 16 years of age complete the measure for how they remember their parents' behaviour towards them during their first 16 years. The measure is to be completed for both mothers and fathers separately. There are 25 questions, including 12 'care' items (e.g., affection, emotional warmth, empathy, and closeness versus emotional coldness, indifference and neglect) and 13 'overprotection' items (e.g. overprotection, intrusion, control, prevention of independence versus independency and autonomy). Each item is scored on a four-grade scale, where $0=$ Very unlike and $3=$ Very likely. High scores indicate a high level of care and overprotection. The PBI is established as having good internal consistency and test-retest reliability, and satisfactory construct and convergent validity (Parker, 1983). The Swedish version of the instrument has also been found reliable (Priebe \& Svedin CG, 2009). Chronbach's alpha was 0.87 in the school sample in the care dimension for mothers ( 0.89 fathers) and 0.80 in the control dimension for both. Chronbach's alpha in the member sample was 0.93 in the care dimension for mothers ( 0.92 fathers) and 0.85 in the control dimension for mothers ( 0.84 fathers). 


\section{Rape myths (IRMA)}

The Illinois Rape Myth Acceptance Scale (IRMA) is used to explore attitudes towards sexual violence and originally consisted of 45 questions. However, we used the shorter version of 22 questions called the IRMA Short Form (IRMA SF) (Payne et al., 1999). IRMA consists of both a general myth component and seven sub-components. In this paper only the general myth component was used. Each item is scored on a seven-point scale, where $1=$ Not at all and 7 = Completely.

High scores indicate high acceptance of sexual violence and rape myths. The cut-off for high acceptance of sexual violence and rape myths is 80 . Chronbach's alpha was 0.87 in the school sample and 0.76 in the member sample.

\section{Analysis}

\section{Study II-III}

Statistical analyses were performed using SPSS version 22.0. Descriptive analyses were used to investigate the different types of sexual behavior among the adolescents and presented as percentages. The differences between male and female participants were investigated by using 95\% confidence intervals. Ordinal data concerning alcohol consumption, self-esteem, sexual and physical abuse, parental relationships, sense of coherence and health were analyzed by using Pearson chi-square. The data were arranged into four different domains - socioeconomics, sexual experience, health factors and abuse and then categorized. In study II categorized into the two groups; sexual debut under14 years of age (early sexual debut) and sexual debut at 14 years of age or older. In study III categorized in the groups; no sexual debut and sexual debut. Univariate analysis was carried out for the variables socioeconomics, sexual experience, health factors, abuse and sexual debut age then categorized into the groups using the early sexual group as index group in study II and the no sexual debut group as the index group in study III. Entering all the statistically significant variables into one model was impossible as there were too many variables for the multiple logistic analyses to handle. To overcome this problem, we performed multiple logistic regression analyses for each variable. The most important variables, those variables that were statistically significant in the multiple logistic regression, were then analyzed in a final multiple logistic regression with all the variables entered into the model. However, this became saturated and a stepwise multiple regression was also performed. Only the final model from the step-wise regression is 
displayed in the Results section in each study.

The number of participants differed between various analyses as not all of the participants answered all the questions.

\section{Study IV}

Initial analyses included Pearson's chi-square test and then single logistic regression was carried out for each of the variables; socioeconomics, sexual experience, health factors and abuse - with the minority sexual group as the index group and heterosexual group acting as the comparison group. As the minority sexual group was set as the index group, all variables entered into the logistic regression models had the most common event as the reference level, in order to capture the factors that contributed the most to a minority sexual identity. Entering all the statistically significant variables into one model was impossible as there were too many variables for the multiple logistic analysis to handle. To overcome this problem, we performed a multiple logistic regression analysis for each table. The most important variables, that is those variables that were statistically significant in the multiple logistic regression, were then analyzed in a final multiple logistic regression with all the variables entered into the model. However, this became saturated and a stepwise multiple regression was also performed.

The outcome was the dichotomized variable for the sexual minority group compared to the heterosexual group.

The number of participants differed between the various analyses, as not all of the participants answered all the questions. All the statistical analyses were performed using SPSS version 22.0. A two-sided $p$ value of $<0.05$ was considered statistically significant.

\section{Results \& Discussion}

\section{Study I}

\section{Family habits and children's interest in reproduction and the body}

We found that when it came to general family behaviour children of both sexes were more likely to have physical contact and co-bathe with their mothers than with their fathers. This gender difference in physical contact seemed to start early since the girls in the study were 
more likely to have physical contact with their parents than the boys. Both boys and girls more often kissed and hugged their mother or co-bathed or had a shower with their mother than with their father. Boys more often had a bath or a shower with a parent of the opposite sex than girls. It was more common among the girls to have a bath or a shower with the parent of the same sex than the boys.

More than half of the children sometimes had a shower or a bath with a sibling, $52 \%$ of the boys and $62.3 \%$ of the girls. There was no different between boys and girls for nudity at home. Approximately $30 \%$ sometimes or more often walked around naked at home.

In general the girls and boys were interested in human reproduction and love and showed interest in the opposite sex. More than 90 percent of the parents had never talked to the children about masturbation. Some of the children had watched pornography, two percent of the girls and $11.1 \%$ of the boys. It was also a gender difference when it came to use of sexwords as it was more common among the parents to have told their sons not to use them than to their daughters. It was more common among girls than among boys to talk about the opposite sex in a negative way. At the same time almost one quarter of both boys and girls did report that the opposite sex was disgusting.

It was more common among girls to worry about their body since close to half of the girls did, compared to approximate one quarter of the boys. On the other hand it was more common among the boys to tease friends or siblings about their body.

Family habits like co-bathing, walking around naked at home or hugging and kissing parents decreased with age while other behaviours such as watching pornographic movies or looking at pornographic magazines increased with age.

\section{Frequently observed and reported behaviour}

An absolute majority of the parents $(97.6 \%)$ believed that their child's interest in sex was normal. Four sexual behaviours were reported by at least $40 \%$ of the parents. These behaviours can therefore be considered as common or frequent and they were:

\section{Asking questions about sex.}

Exploring own body and genitals.

Talking about sex (Boys).

Touching genitals at home (Boys). 


\section{Infrequently observed and reported sexual behaviour}

Infrequently observed sexual behaviours were defined as sexual behaviours reported by three percent or less of the parents. Many of the sexual behaviours we asked about ended up as infrequent.

Nine behaviours were not reported by any parent:

Putting object in the vagina or anus.

Making oral contact with other children's genitals.

Asking other children to participate in sex activities.

Masturbating in public. (Girls)

Sexually harassing other children. (Girls)

Being more interested in sex than children of the same age-(Girls)

Having the desire to be the opposite sex. (Boys)

Trying to kiss other children with the tongue. (Boys)

Being too friendly with men whom the child does not know well. (Boys)

Other behaviours that were reported as unusual (3\% or less) for both sexes were:

Rubbing the body against other people or objects.

Touching other children's genitals.

Imitating intercourse with other children.

Showing genitals for other children.

Searching for a clinging body contact.

Trying to kiss adults with the tongue.

Masturbating in public.

To touch the genitals in public was unusual among girls $(0.8 \%)$ and is somewhat more common among boys (6.3\%). To masturbate in public was uncommon in both sexes, $1.6 \%$ of the boys and none of the girls were reported. No girls were reported to have been seen masturbating using a hand either often or even daily, but $6.1 \%$ were reported as having been seen doing this infrequently, that is less than once a month. Among the boys $9.6 \%$ were 
reported as having been seen masturbating with their hand, $1.2 \%$ were reported as having been seen masturbating with their hand often or daily and $3.6 \%$ at least once a week.

\section{Gender differences}

There were some gender differences; girls more often asked questions about dating, were worried about their body, talked in a negative way about children of the opposite sex and dressed as the opposite sex. Boys more often explored their body and genitals, asked parents questions about sex, talked about sex, teased a sibling or a friend about his or her body, touched their genitals at home and in public, used sex-words, and showed genitals for adults.

\section{Age differences}

Some behaviours differed with age. Family habits like hugging or kissing parents, having a bath or a shower with sibling or parent, and walking around at home naked were all behaviours that decreased with age. Some sexual behaviour also became less common with the increasing age of the child. Examining genitals and touching genitals at home, spreading one's legs, touching genitals in public or other children's genitals, showing genitals for other children, trying to or touching mother's or other women's breasts, and watching people undressing or when naked were all behaviours that decreased with age. Some family habits and behaviours significantly increased with age: watching pornographic movies or looking at pornographic magazines, and being reprimanded after watching a pornographic movie or looking at a pornographic magazine, teasing siblings about their body, asking questions about sex and, finally, talking about sex.

\section{Discussion}

The goal of this study was to illuminate issues that arise around the sexual behaviour of school children, age 7-13, as observed by their parents. The reported sexual behaviours were divided into frequent and infrequent behaviours. The results in the study may be summarized in four main findings:

The parents reported a number of behaviours, both general and sexual. The reports about the children's general behaviour showed different gender preferences and gender differences in physical contact. Nearly $90 \%$ of both girls and boys mostly played with friends of the same 
sex. Girls were more physical with both parents and friends than boys and this gender difference was also found among the parents since the mothers were more physical with their children than the fathers. The mothers also received more physical contact since the children were more physical with them compared to their fathers.

Children are curious about sex. Our study confirmed that children in this age group are curious about sex, which was reflected in the most commonly reported behaviours among both boys and girls. The children had questions about sex, talked about sex, expressed or showed interest in the opposite sex and were interested in love and reproduction. Compared to behaviours reported in other studies, Swedish children in this age group showed great curiosity about sex. In an American study, Ott and Pfeiffer (2009) showed age differences in sexual curiosity, and a majority of the 11-year-old children in their study described sex as "something nasty". Sexual curiosity was seen among the older participants and the 13 year olds expressed a desire to learn more about sexuality in general. These somewhat divergent findings could of course reflect the effect of cultural differences seen in some other studies but care should be taken without knowing more about each study group (Larsson \& Svedin, 2000). An absolute majority of the parent's in our study believed that their child's interest in sex was normal $(97.6 \%)$.

Explicit sexual behaviours were unusual among the children. Many of the explicit sexual behaviours, for example masturbating or touching/showing genitals in public, were reported as unusual. One reason is probably because it is part of the normal socialisation process to learn that any kind of touching genitals in public is not a socially acceptable behaviour. Normally developing children learn to be discrete and selective in the display of certain behaviours such as, for example, masturbation or touching genitals in public (Casteel \& Mallants, 2008).

Other infrequent sexual behaviours among the children in the study could be described as (a) imitation of adult behaviour, for example imitating intercourse or oral contact with other children's genitals, (b) breaking personal boundaries such as rubbing the body against other people, touching other children's genitals or kissing strangers or (c) self-stimulation by, for example, putting objects into the vagina or anus. The infrequency of these behaviours is not to be seen as an indication of lack of interest in sexuality among the children but instead it probably reflects the socialisation increasing with age as pointed out by Larsson et al, (2000). Children learn not to act out their sexuality in an explicit way and as a result the parents do 
not know all of the children's behaviours and cannot report them. This can explain why retrospective studies tend to show higher frequencies; adult individuals can self-report behaviours in childhood that they never would have displayed if a parent had been present. Four percent of female college undergraduate students recalled having oral-genital contact during childhood (Lamb \& Coakley, 1993) and in a self-report study of child welfare and mental health some adult workers asked to recall sexual behaviours when they were 13 years old or younger. Among the study population 16 percent recalled simulating intercourse with other children and five percent remembered inserting an object into the vagina or rectum of another child (Johnsson, 2009). This indicates that it is uncommon for children to show this kind of behaviour in public and when such behaviour is done openly it might have its roots (traumatic response) in exposure to events such as domestic violence and sexual abuse (Kendall-Tackett et al., 1993; Silovsky \& Niec, 2002; Friedrich et al., 2002) or exposure to sexually explicit material such as pornography (Johnson, 2009) or even being a sign of social under stimulation (Leung \& Robson, 1993; Satterfield, 1975). Further studies are needed to explore the relationship between these unusual behaviours and specific childhood experiences.

Some behaviours changed over time, which has been reported earlier (Reynolds et al., 2003) probably as a part of the child's normal socialisation. The frequency of showing and touching genitals in public and trying to touch mothers' or other women's breasts decreased with age. Some behaviours increased, for example asking and talking about sex, which could indicate a growing interest in sex as the child becomes older.

\section{Study II}

\section{Sexual debut}

A total of 258 students $(7.5 \%)$ had had their sexual debut before the age of $14(7.8 \%$ girls and $7.2 \%$ boys), $2,211(64.4 \%)$ had had their sexual debut at the age of 14 or older $(66.4 \%$ girls and $62.2 \%$ boys) and $963(21.1 \%)$ had not yet had their sexual debut (25.8\% girls and $30.7 \%$ boys). The mean age for sexual debut was 15.4 years. The girls had an earlier debut, with a mean age of 15.3 years while the boys had a mean age of 15.5 years. 


\section{Socio-demographic background}

Early sexual debut was negatively correlated with living with both biological parents or alternating between them. It was also more common to be in a practical or individual school programme than in an academic programme among the adolescents with an early sexual debut. There was no correlation between time for sexual debut and parental educational background or immigration status of the child or of the parents.

The Parental Bonding Instrument (PBI) was used to measure parental support in two categories: care and overprotection/control. There were no differences between girls in the two sexual debut age groups regarding parental care and overprotection/control. However, the boys with an early debut did more often report less caring mothers or fathers as well as overprotection/control from mothers compared to the rest of the boys.

\section{Sexual behaviour}

The majority (90\%) of the adolescents were heterosexual, $0.6 \%$ were homosexual, $3.6 \%$ were bisexual and $5.9 \%$ were not sure.

It was more common among bisexual girls to have had an early sexual debut than among heterosexual girls and the same pattern was detected among the homosexual boys.

The early debut group reported a higher number of sexual partners. A vast majority of all adolescents $(88.7 \%)$ had experience of oral sex. The adolescent in the early debut group were more sexually experienced as it was more common with both oral and anal sex in that group compared to the rest.

\section{Health and health behaviour}

Both girls and boys who smoked were more likely to have an early sexual debut. This was also evident for boys who drank more than four times a month. A higher percentage of the total early sexual debut group $(15.2 \%)$ had tried more than a sip alcohol before the age of 11 
or younger, compared to $3.9 \%$ in the older group, and they were more likely to have got drunk $(15.5 \%)$ at the age of 12 or younger, compared to $2.7 \%$ in the older group.

Adolescents with an early sexual debut were also more likely to have tried different kinds of drugs, such as heroin, cocaine, ecstasy or amphetamine at 18 years of age. Having used hashish/marijuana doubled the odds for early sexual debut among girls and increased the odds fourfold for boys.

The teenagers were also asked about antisocial behaviour, namely having been away for one night without their parents knowing, having been in a fight or hurt someone, having hurt animals, having been violent with a teacher and having threatened or bullied someone. Adolescents with an early sexual debut were significantly more active in these kinds of antisocial behaviour than the adolescents with a later sexual debut and it was much more common for boys to be physically violent towards both people and animals.

To assess the adolescents' sense of coherence, The Sense of Coherence Scale (SOC) was used. There was a difference among the boys in our study, with a low sense of coherence almost doubling the odds of having had an early sexual debut.

The Rosenberg Self-Esteem Scale showed a significant difference among boys. Boys with lower self-esteem were more likely to have an early sexual debut than those who did not.

Symptom of depression and anxiety during the previous week, were measured using the Symptoms Checklist 25. Boys who reported more signs of anxiety and depression had an earlier sexual debut than those who reported fewer signs.

\section{Experience of sexual and/or physical abuse}

It was more than twice as common for the girls in the early debut group to have had experience of sexual abuse than for the girls with a later debut. Of all the adolescents, $1.5 \%$ stated that they had sold sex - that is they had displayed their genitals, been photographed or filmed, had masturbated for someone, had had oral sex, vaginal or anal intercourse or had been photographed or filmed in sexual situations for payment. This was nearly seven times as 
common among the boys with an early debut and five times as common among the girls with an early debut compared with boys and girls respectively with a later debut

Experiences of different kinds of physical child abuse (been pushed or shaken, had something thrown at them, been hit with an object or a hand, been kicked, burnt or scalded) among boys were more common in the early debut group. For example; it was seven times as common to have been burnt or scalded among the boys in the early debut group compared to the boys with a later debut The results were similar among the girls: experience of physical child abuse increased odds of having had an early sexual debut.

\section{Multivariate analyses}

Being female increased the risk of an early sexual debut while living with both biological parents, or alternating between them, seemed as a protective factor since it decreased the risk. Among the sexual behaviour variables, the number of sexual partners was positively associated with an early sexual debut, as was experience of anal sex.

In the category health and health behaviour, antisocial behaviour and using drugs were more common among the adolescents with an early sexual debut. Adolescents who had tried heroin, cocaine, ecstasy or amphetamine were more likely to be found in the early sexual debut group.

Both boys and girls with an early sexual debut displayed more antisocial behaviour, as they were more often staying away from home overnight without their parents' knowledge, were violent with a teacher more often and were more likely to threaten or bully someone.

\section{Discussion}

This study compared adolescents with an early sexual debut with young people with a later sexual debut. The assessment, carried out at the age of 18 , covered background factors, health behaviour, mental health and experience of sexual and/or physical abuse.

We found that the mean age for sexual debut in this sample was 15.4 years and $7.5 \%$ had their sexual debut before the age of 14 . The slightly lower debut age among girls could be 
explained by the fact that girls tend to have an earlier onset of puberty than boys and this correlates positively with an early sexual debut (Downing \& Bellis, 2009; DeGenna et al., 2011).

Living with both biological parents, or alternating between them, seemed to be a protective factor for having an early sexual debut for both girls and boys in the univariate analysis as well as in the multiple analyses. This finding is supported by earlier research showing that adolescents from two-parent families were less likely to have sex and had fewer sexual partners (Price \& Hyde, 2009; Haglund \& Ferring, 2010). Similar findings from a Greek study showed that adolescents with an unstable home environment, due to divorce, recent death, or not living with their mother, were more likely to be sexually active (Tsitsika et al., 2010). Cavazos-Regh et al. (2010) claimed that living with both parents was a protective factor, except for when the mother was very young, poorly educated, or if either of the parents had alcohol use disorder. Goldberg (2012) described a link between family stress or impaired families and both early sexual debut and risky sexual behaviour. He also provided a description of the connection between early sexual debut and later risky sexual behaviour. Parents with low care or an overprotective/controlling parental style seemed to be a risk factor for early sexual debut, especially for boys. With regard to parental education there was no significant association with early sexual debut, as earlier studies have shown (Valle et al., 2009, Price \& Hyde, 2009), or being an immigrant or having been born in Sweden to immigrant parents.

Both girls and boys with a sexual debut before 14-years-of-age had had more sexual partners and as much as two-times more experience of anal sex at the age of 18 than girls and boys with a later sex debut. An early debut might explain the experience of having more sexual partners, simply because they have spent more time engaging in sexual activity. It could, however, also indicate a trend of increased risk-taking sexual behaviour (Landsford et al. 2010), as well as other risky behaviour, such as substance use and anti-social behaviour (Price \& Hyde, 2009, Cavazos-Regh et al., 2010).

Different forms of antisocial behaviour were more frequent among both girls and boys in the early debut group and three out of five stayed significant in the multiple analyses (staying away from home overnight without their parents' knowledge, violent with a teacher and threaten or bully anyone. Together with the increased use of drugs, this clearly indicated a connection between early sexual debut and risky health behaviour. Earlier Swedish studies 
showed that when a teenager had his or her sexual debut when 14-years-old or younger there was already a risk of developing a hazardous lifestyle involving more use of tobacco, alcohol, and drugs and being more involved in physical violence (Makenzius \& Larsson, 2012). Others researchers like Cornelius et al (2007) have shown a correlation between early sexual debut and a higher risk of early development of substance use disorder. In summary, these findings are in line with the results of other studies (Price \& Hyde, 2009, Ramrakha et al., 2007), which highlighted the fact that antisocial behaviour and early sexual debut were linked to each other and could be explained by a common trait to test the limits of their behaviours.

Most of the significant health and health behaviour variables did not remain significant in the multiple analyses and deteriorating health, low self-esteem and low sense of coherence at the age of 18 were better explained by other factors than an early sexual debut.

Finally, experience of sexual abuse, especially among girls, and physical abuse, especially among boys, and sexual exploitation were more prevalent in the group of young people with an early sexual debut. This indicated, as other researchers have shown, that there is a connection between early sexual debut and sexual and physical abuse (Valle et al., 2009; Pedersen \& Skrondal, 1996; Dahle et al., 2010). It is important that professionals and parents are aware of this as it could be a threat to the psychosocial health of adolescents, especially as young people often don't tell anyone they are being, or have been, abused (Svedin \& Back, 2003).

In conclusion, early sexual debut correlated with a series of problematic behaviours that could have an impact on psychosocial health later in life. Our study revealed a trend that showed that when boys had an early sexual debut it had an impact on their psychosocial health, with low sense of coherence, low self-esteem and a greater incidence of anxiety and depression than boys with a later sexual debut. Parents, teachers and healthcare providers need to be aware that an early sexual debut is associated with increased vulnerability in some children and that has to be addressed. 


\section{Study III}

\section{Sexual debut}

There were 3,380 adolescents in our study and 830 (24.6\%) had not made their sexual debut at the age of 18 (22.4\% girls and 27\% boys). They formed the index group. The remaining 2,550 had made their sexual debut and they formed the comparison group. The mean age for sexual debut was 15.4 for the total sample, 15.3 for the girls and 15.5 for the boys.

\section{Socio demographic background and parental bonding}

Male and female adolescents who had not made their sexual debut were significantly more likely to be living with their biological parents and less likely to be living on their own, in boarding schools, institutions or foster care. Girls who were born outside Europe or had parents who were born outside Europe were three to five times less likely to have made their sexual debut. There was almost no difference between the groups when it came to girls and parental bonding, but the boys in the index group were more likely to have relationships with their parents that were based on care and normal control.

\section{Sexual behavior and attitudes}

Twice as many boys and girls in the index group were unsure about their sexual identity than peers who had made their sexual debut. The adolescents in the index group reported lower sexual lust and use of pornography than the boys and girls in the comparison group. The boys in the index group were 10 times more likely to report that they never or seldom felt sexual desire than the boys in the comparison group and this was 56 times higher among the girls in the index group than the girls in the comparison group. The odds ratio for never having watched pornography was more than double for the boys in the index group and six times higher for the girls in the index group. There was no difference concerning attitudes towards sexual violence, based on rape myth acceptance, between the boys, but the girls in the index group were more likely to have tolerant attitudes towards sexual violence than the girls in the comparison group, with an increase in odds ratio of 1.64 .

\section{Health and health behavior}

Boys and girls in the index group were less likely to smoke or use alcohol and drugs than adolescents in the comparison group, with the adolescents in the index group showing 
increased risks that varied between two and 16. In addition, the index group reported less antisocial behavior. It was more common for the adolescents in the comparison group to stay away from home at night without their parents' knowledge, be in a fight, demonstrate antisocial behavior or hurt someone. Boys in general were more likely to hit or hurt animals and were more violent to teachers than girls, but the boys in the index group were less likely to demonstrate such behavior than the boys in the comparison group. No difference in sense of coherence and self-esteem was found between the two groups. Girls in the index group had better mental health scores than girls who had made their sexual debut.

\section{Experience of sexual and/or physical abuse}

Experience of child abuse was less common among both boys and girls in the index group. Those in the comparison group had increased odds ratios for sexual abuse and physical abuse. None of the adolescents in the index group had ever sold sex.

\section{Multiple analyses}

Being male increased the adjusted odds ratio of adolescents not having made their sexual debut at the age of 18 , as well as living with both biological parents or alternating between them.

It was more common for adolescents in the index group to have a parent born outside Europe. Parental bonding style also had an impact. Adolescents whose fathers had normal to high caring parental styles demonstrated a 1.37-fold increase in their adjusted odds ratio for not having made their sexual debut by the age of 18 .

When it came to sexual behavior and attitudes, the multiple analysis showed that it was more common for adolescents in the index group to be unsure about their sexual identity than adolescents who had made their sexual debut. Adolescents in the index group showed little interest in sex, had low or no sexual desire and consumed very little pornography.

With respect to health behavior, no sexual debut at 18 years of age correlated positively with no alcohol and tobacco consumption. 
Adolescents in the index group reported significantly less experience of child abuse than the adolescents with a sexual debut.

\section{Discussion}

This study compared adolescents who had not made their sexual debut by the age of 18 with adolescents of the same age who had become sexually active, against a set of background factors. These were socio-demographics, health behavior, sexual behavior and attitudes, mental health and experience of sexual and, or, physical abuse.

Adolescents living with both biological parents or alternating between them seemed to postpone their sexual debut. This is supported by earlier research, from both western and nonwestern countries, that an intact household or dual-parent families was seen as a protective factor (Cavazos-Regh et al., 2010; Haglund \& Ferring, 2010; Lammers et al., 2000) and that family stress or impaired families were associated with risky sexual behavior and early sexual debut (Tsizika et al., 2010; Goldberg 2013). This family cohesion was also strengthened by the adolescents in the index group, especially boys, who perceived their fathers as more caring.

Immigration status mattered, especially for girls. Girls born outside Europe or with a parent born outside Europe were less likely to have made their sexual debut than girls born in Sweden. As earlier studies have reported, there were considerable ethnic differences linked to the age of sexual debut, presumably depending on social expectations in different cultures and communities (Kinsman et al., 1998). However, further research about the age of sexual debut, with regard to values, culture, ethnicity and biological factors, would add valuable information.

Adolescents in the index group watched less pornography and reported lower sexual desire than the comparison group. This implied that those with low sexual interest and desire might make their sexual debut later than their peers. Since there was no information about their testosterone levels or status or stage of puberty in this study, and as testosterone levels correlate with desire (van Anders, 2012), no correlations between hormone levels or the onset of puberty and sexual debut could be established. Also, we could not establish any correlations due to other biological factors, such as neurotransmitter levels or medication that interact with libido (Arigolas \& Melis, 2003; Cascade et al., 2009). Since dopamine is 
associated with reward-related behaviors (Hull, 2004) which can include sexual behaviors, one possible theory could be that the adolescents who had not made their sexual debut had low levels of dopamine or that they had not yet experienced the chemical rewards of sexual activity. Because serotonin has an inhibitory influence on libido (Hull, 2011), it would have been useful to know how many of the adolescents who had not made their sexual debut were on SSRIs or had high serotonin levels for other reasons.

Another contributing factor towards no sexual debut could be the fact that adolescents in the index group were more likely to be uncertain about their sexual identity.

The adolescents in the index group used less alcohol, tobacco or other drugs and showed less antisocial behavior than adolescents of the same age who had already made their sexual debut by the age of 18 and especially compared to adolescents with an early debut, defined as voluntary sexual intercourse before the age of 14 .

Finally, adolescents in the index group had less experience of sexual abuse than adolescents who had made their sexual debut by the age of 18 , which supported findings in previous research (Dahle et al., 2010; Valle et al., 2009). There was nothing to support the fact that sexual abuse early in life could result in a delayed consensual sexual debut.

Taking all the information together, adolescents with no sexual debut at the age of 18 seemed to live a more stable and more cautious life than peers with more sexual experience. The results tended to be similar to the over-controllers described by Baams et al. (2014) This was also underlined by the fact that girls in the index group seemed to have more balanced mental health, since they expressed a normal to high sense of coherence more often and reported better mental health than girls in the comparison group. Since this finding didn't belong to any primary aim of the study we suggest that personality traits need to be explored in future studies of young people with late sexual debut.

\section{Main conclusions}

Adolescents who had not made their sexual debut by the age of 18 seemed to have lived a more stable life than their sexually experienced peers, as they were more likely to live with 
one or two biological parents and had fewer abusive experiences. Culture or immigration status seemed be more important to girls, since those who had not made their debut were more likely to have had a parent born outside Europe. Adolescents who delayed their debut also tended to have more conservative attitudes, as they were less likely to consume pornography, alcohol and tobacco and reported less antisocial behavior. They also reported lower levels of sexual desire than adolescents who had made their sexual debut. This provides relevant information in the scientific field of sexual behavior among adolescents and contributes to the earlier knowledge of the age of sexual debut and its associations. This can constitute valuable public health information for parents and professionals, as they could be made more aware that early sexual debut could be associated with various risk behaviors, such as alcohol, tobacco and drug consumption, antisocial behavior and experience of sexual abuse. It could also provide an argument in the debate about the advantages of waiting to have sex, as having sex for the first time under the age of 14 can lead to poor psychosocial health and risky behavior in later life.

\section{Study IV}

\section{Family socio-demographics and parental relations}

The index group comprised the RFSL members and sexual minority school sample and consisted of 708 adolescents and young adults with the mean age of 18.25 years, while the comparison group consisted of 3,107 heterosexual adolescents with a mean age of 19.9 years. The mean age of the RFSL members was 21.45 and the mean age of the school minority group was 18.40 years.

The subjects in the index group had a higher mean age and were less likely to live with their biological parents than the heterosexuals in our study. The parents of subjects in the index group were more likely to be unemployed, on sick leave or pensioners compared to the parents of the comparison group who were actively engaged in employment, studies or parental leave to a higher extent. There was no difference in parental education between the index group and the comparison group but between 7-19.6\% of the adolescents did not know if their parents had studied at a university or not so the actual percentages remain uncertain. The comparison of subgroups in the index group showed that the parents to the adolescents who claimed sexual identity as "none of the above" were better educated than the rest of the 
parents with more than half percent with university studies (fathers $61.3 \%$ of the fathers and $54.8 \%$ of the mothers).

When it came to the adolescent's immigrant status, there was no difference between the groups, but it was more unusual to have a parent born outside Europe in the index group than in the heterosexual group.

The adolescents and young adults in the index group were significantly more likely to have child-parent relationships based on low care and overprotection than the comparison group.

\section{Sexual behaviors and attitudes}

Approximately $80 \%$ (80.4\% in the index group and $80.6 \%$ in the heterosexual comparison group) of the participants had made their voluntary sexual debut. Subjects in the index group were nearly three times as likely to have had an early sexual debut, defined as voluntary intercourse when they were younger than 14 years, than the comparison group. There was a considerable difference in sexual experiences, as it was more common to have experience of oral and anal sex in the index group, while vaginal sex was more common in the heterosexual group. In the index group, RFSL members were significantly more experienced than the school participants. More than half of the RFSL member group had an experience of anal sex, compared to $30.1 \%$ in the minority school group and $23.1 \%$ of the heterosexuals. When it came to oral sex, the RFSL member group was the most experienced with $87.3 \%$, compared to the minority school group with $62.7 \%$ and the heterosexual group with $66.5 \%$.

The vast majority of the adolescents said that they had watched pornography, but watching pornography was more common in the index group.

The graphed results for the adolescents and young adults in the index group have the shape of a U-formed curve with both lower and higher sexual lust than the heterosexuals. The RFSL members in the index group reported higher sexual lust than the minority school group and the heterosexuals.

Among the index group 53 individuals described themselves as a transperson, Of them, eight defined themselves as transsexual, one as transvestite, four as transgenderist, seven as female to male (FtM) or male to female (MtF), four as crossdresser, nine as dragqueen or dragking, two as boychick, and six were unsure and twelve as other.

Approximately $20 \%$ of the total study cohort reported high rape-myth acceptance. There was no difference between the index and comparison groups, but the school minority group 
reported significantly higher rape myth acceptance (28.3\%) than the RFSL member group $(20.6 \%)$.

\section{Health and health behavior}

Subjects in the index group were more likely to use alcohol and drugs than adolescents in the comparison group.

A low sense of coherence, low self-esteem and worse mental health were more common among the index group than the heterosexual comparison group. When it came to sense of coherence, nearly half of the school minority group (47.1\%) reported a low sense of coherence, compared to $22.2 \%$ of the RFSL member group and $25.4 \%$ of the heterosexual comparison group. The same pattern could be seen for low self-esteem $(37.3 \%, 19.1 \%$ and $19.3 \%$ respectively) and worse mental health $(41.9 \%, 20.1 \%$ and $18.8 \%)$ respectively.

\section{Experience of child abuse and selling sex}

Experience of different kinds of child abuse was significantly more common in the index group. Penetrating sexual abuse was reported by nearly one in four of the total index group (24.9\%), with a slightly higher frequency in the RFSL member group (28.4\%) than the school minority group (21.5\%) and $7.1 \%$ of the heterosexual group. Nearly half (46\%) of the individuals in the index group had experienced physical child abuse, compared to $30.6 \%$ of the heterosexual group. There was also a significant difference between the groups when it came to sexual exploitation, with $7.6 \%$ of the index group and $0.9 \%$ of the heterosexuals reporting that they had sold sex. When comparing between different minority groups the sexual identity group "none of the above" had the highest frequencies of sexual abuse (41.9\%), sold sex (12.9\%) and physical child abuse (54.8\%).

\section{Multiple analyses}

The subjects in the index group were less likely to have had a parent born outside Europe than the heterosexual group. When it came to sexual behavior, the index group had more experience of anal sex and less experience of vaginal sex compared to the heterosexual group. When we measured psychological quality of life, we found that adolescents and young adults in the minority group had lower self-esteem and worse mental health than their heterosexual peers. Having a minority sexual identity doubled the risk of having experienced penetrating 
sexual abuse as well as having been sexually exploited. In addition, physical child abuse correlated positively with having a sexual minority identity.

\section{Discussion}

This study compared 708 index group adolescents and young adults with a comparison group of 3,071 heterosexual adolescents, against a set of factors. These included family sociodemographics, health behavior, sexual behavior and attitudes, mental health and experience of sexual and, or, physical abuse.

The child-parent relationship was more commonly characterized by low care and high overprotection/control in the index group and these factors were higher in the school group than the RFSL member group. As earlier studies have shown, the sexual identity of a child can affect the child's relationship with his or her parents. Rosario et al. (2014) even pointed out that mothers are less affectionate to their homosexual or bisexual child than the child's heterosexual siblings. Since the RFSL members in the index group were older, maybe their relationships with their parents had less impact on their lives and maybe they lived in an environment that was more tolerant of sexual minorities and this made it easier for them to live their lives.

It is also plausible that the kind of support that an organization like RFSL offers provides a protective factor. Ybarra et al. (2015) claims that LGBT youths are more likely to have friends online and value them more than friends in real life than heterosexual youths. McKenna \& Bargh observes that online discussion and especially playing an active role in online discussion groups may help people to become comfortable with their sexual identity and coming out (1998).

Earlier research reported that LGBT youth seemed more sexually active and it was more common from them to have a very early sexual debut, higher numbers of sexual partners and more experience of oral and anal sex (Tornello et al., 2014). This was true for both of our minority groups, but was most pronounced in the RFSL member group, which may be due to them being older and having more sexual experiences.

The school minority group reported a weaker sense of coherence, lower self-esteem and poorer mental health than the heterosexual group and also the RFSL member minority group. One reason for their lower health status could be that they were in an earlier stage of the 
process of formulating their sexual identity for themselves and coming out to others. This may cause them to hesitate to seek medical care and may even result in avoidance of routine healthcare due to fear of stigmatization by the medical community (Dahan et al., 2007).

In some previous studies, mental health issues among the sexual minority group were believed to depend on external and internal negativity to sexual minorities (Hatzenbuehler et al., 2014; Kuyper \& Fokkema, 2011). Perhaps the levels of mental disparities among the Swedish adolescents and young adults in this study were lower than they would have been in countries with more external negativity than in Sweden. Collier et al compared attitudes towards homosexual adolescents in the Netherlands and USA and found that greater acceptance in the Netherlands affected LGBT youths in a positive way (Collier et al., 2015).

It is important to explore the quality of life of LGBT youths so that we can prevent them from experiencing low mental and physical health when they become adults. An Australian study of a crisis helpline showed that one predictor of being a frequent caller, defined as a person who made at least 0.667 calls per day in a period ranging from one week to 549 days, was being transgender. The study also found that other issues that predicted frequent calls were suicidal tendencies, self-harm, mental health issues, crime and domestic violence. (Spittal et al., 2015) To be a member of an organization such as RFSL might have offered a higher quality of life than the quality of life that the school minority group experienced because associating with sexual minority peers could have been protective and would probably have helped them to feel less lonely. To be member of an organization is a way to belong and to feel included and would improve the quality of life. On the other hand, being active and deciding to belong to an LGBT organization could also reflect a certain kind of personality that could explain the differences in this study. Further studies about what kind of people do or do not belong to an LGBT organization are needed to fully understand the complexity of reported self-esteem and mental health.

There was a positive correlation between having a minority sexual identity and of having experience of both penetrating sexual abuse and physical abuse, as earlier research has also shown (Reisner et al., 2014; Roberts et al., 2010; Saewyc et al., 2006). There were, however, no significant differences between the school minority group and the RFSL member group.

The adolescents and young adults with the sexual identification "none of the above" had the most well educated parents and also the most experience of penetrating sexual abuse, selling 
sex and physical abuse as a child than the other sexual identification groups, which emphasise the importance of searching for abused children and adolescents in families in which some or all members are well educated as well and maybe even more carefully among adolescents who show an uncertainty about their sexual identification.

It is very important that professionals become aware of the fact that more than one-third of homo-, bisexual or unsure adolescents have experience of penetrating sexual abuse and nearly half of them have experienced child abuse.

In this study $2.1 \%$ of the subjects had sold sex. A Swedish study of 2951 subjects aged 15-25 years in 2009 reported $1.7 \%$ (Ungdomsstyrelsen, 2009). The prevalence in our index group was high $(7.6 \%)$ compared to the heterosexual group $(0.9 \%)$. There was no difference between the school minority and the RFSL member group.

\section{GENERAL DISCUSSION}

\section{Summary of findings and clinical implications and reflections}

The aim of the research leading to this thesis was to study sexual behaviour, debut and identity among Swedish children, adolescents and young adults. Among the children the focus was to investigate sexual behaviours, types and frequencies as reported by their parents to give parents and health-care providers greater knowledge about what can be considered common sexual behaviour among children between 7 to 13 years of age and what to consider as unusual. This aim was met in study I. In study II the focus was on early sexual debut and its associations comparing adolescents with a sexual debut at an age younger than 14 with adolescents with a later sexual debut. Factors investigated were socio-demographics, sexual experience, health, drug-use, child abuse and present behaviour at age 18 . To find out more about adolescents who had not had their sexual debut at least up to age 18 and associations 
with this situation, we used the same material as in study II but focused on the adolescents and young adults with no sexual debut (no oral, vaginal or anal sex at the age of 18 years) and compared them with their peers with experience of oral-, vaginal- or anal sex. We studied the relationship between no sexual debut and socio-demographics, physical and psychological health, sexual behavior and history of sexual abuse. Finally in study IV the focus was on sexual identity and especially on comparisons between a sexual minority identity group and a heterosexual identity group with respect to family socio-demographics, sexual experience, health, experiences of child abuse, sexual exploitation and present behaviour.

The studies showed that sexuality and sexual behavior among children, adolescents and young adults are important parts in their development and daily life but that there is still much to discover in this area of research. The following paragraphs collectively summarize and highlight the main findings.

\section{Common and uncommon sexual behaviours among schoolchildren}

The schoolchildren in study I showed many sexual behaviours that usually are described as non-problematic, expected, common or normal. The parents reported for example several explorative sexual activities such as asking questions about sex, talking about sex, expressing interest in the opposite sex, love and reproduction. The children did not present many sexualized or problematic sexual behaviours. These results are well in line with earlier research that claims that problematic sexual behaviours or sexualized behaviours are rare in a normative population but can be seen among children with underlying emotional problems or as a precursor to sexual offending (Dahle et al. 2010; Friedrish et al., 1992; Larsson \& Svedin, 2001; Wiekowski, Hartsoe, Mayer \& Shortz, 1998). Examples of uncommon or problematic sexual behaviour are, for example, sexual play between children accompanied by anger, fear or anxiety (Bonner, Walker \& Berliner, 1999), sexual play that is potentially physically and/or emotionally harmful to self or others, developmentally inappropriate knowledge or sexual activities, sexual play that involves genital and/or mouth contact (Silovsky \& Bonner, 2003). The behaviours that were common among the schoolchildren in our study (mostly explorative behaviours) were comparable with the behaviours Cavanagh Johnson (1995) listed as common and expected in the same age group. This gives us reason to always be ready to react when a child shows sexualized, uncommon or unexpected sexual behaviour. In such cases it is of great importance to reach out to the child and carry out an 
investigation of the observed behaviour as well as about physical and emotional status. A clear pattern among the schoolchildren was also that sexual behaviours correlated with age as seen in previous studies (Bancroft, 2003; Larson \& Svedin, 2001). Some sexual behaviours decreased with age probably because the child gets socialized (Heiman, Leiblum et al., 1998; Larsson \& Svedin, 2001) and some increased as the child grew older. If a child continues to present behaviours that should decrease with age, for example showing genitals in public, this has to be seen as uncommon and problematic and should draw attention from adults and professionals concerning the child.

Clinical implication and reflections. Children with experience of sexual abuse usually do not often tell anyone about it but sometimes they show uncommon or sexualized behaviours (Deblinger et al., 1989; Finkelhor, 1979; Friedrich et al., 1991; Friedrich et al., 1992). There can be many different reasons why they do not tell anyone. Sometimes they may not be aware that they are victims of sexual abuse or have experienced abuse earlier in life. For example, young children and toddlers might not be aware that what they are experiencing is abuse; they might think it is a normal behaviour and something that happens to every child or in every family. The abuse can also occur when they are asleep or sometimes even drugged. They might not be able to tell anyone if they do not yet have the language needed to describe what they have experienced. Sometimes the perpetrators bribe or threaten the child not to talk to anyone about the abuse. The threats can include harm to person, siblings, mother or pets. The child usually takes the threat seriously and does as the perpetrator says. Many children and adolescents report that they are ashamed about the abuse and feel guilt. When I see abused children as a clinician I sometimes ask why they did not tell anyone and quite often they tell me that no one ever asked them about it.

Sometimes a child's' sexual behaviour causes concern. There is no sexual behaviour in particular that is exclusively engaged in by sexually abused children (Friedrich et al., 1992) but unexpected sexual behaviours among children often causes concern among the adults close to the child. As a clinician I often receive questions about children's behaviours, both general behaviours and sexual behaviours. Even though there are no certain psychological symptoms of sexual abuse a sexualized or uncommon sexual behaviour can be a sign of experience of sexual abuse or neglect. Therefore it is essential to have as much knowledge as possible about which sexual behaviours are uncommon and therefore red flags, and which are expected and frequent at different ages. An example of "red-flag behaviour" is aggressive sexual behaviour, children forcing other children to sexual activities, compulsive sexual 
behaviour or behaviours imitative of adult sexuality (Cavanagh Johnson \& Friend, 1995; Kellogg, 2009). When any of the behaviours above are seen or reported, attention must be drawn to the child. These are uncommon and an unexpected behaviours. The child might have experienced sexual abuse, processing it though play or paintings or might have access to pornography (a form of neglect) or have actually seen a genuine sexual act. Since research about school children's sexual behaviour is still not as well developed as we believe it should be, I hope it can be of value for professionals to use the results reported in this thesis and the published papers on which it is based as aids in determining which sexual behaviours are common and to be expected in children from 7 to 13 years of age and which behaviours need attention from adults.

\section{Sexual debut age and its associations with mental health and risk behaviours}

Mental health and debut age are correlated for both the girls and boys in this study as has been reported earlier (Meier, 2007). Boys who reported more signs of anxiety and depression had an earlier sexual debut than those who reported fewer signs. Researchers have also previously reported that children and adolescents with mental health issues and in psychiatric care more often have an early sexual debut, engage in higher rates of sexual risk-taking (Brown et al, 1997; Donenberg et al., 2001) and have a higher number of sex partners than their peers (Donenberg et al., 2001, 2002). Girls in study III with no sex debut at 18 reported better mental health scores than girls of the same age who had made their sexual debut. These findings taken together indicate that poor mental health and early sexual debut are correlated.

We also found a correlation between an early sexual debut and other risk behaviours, as has previously been reported by a number of researchers (Compian, Gowen \& Hayard, 2004; Cornelius et al, 2007; Johansson \& Ritzén, 2005; Pedersen \& Skrondal, 1996; Ramrakha et al., 2007;). The adolescents in our study with an early debut had a higher number of sex partners, more advanced sex, consumed alcohol, tobacco and other drugs to a higher extent and reported antisocial acts to a higher extent than their peers with a later sexual debut. Sexual identity and use of alcohol and other drugs also seemed to correlate since the adolescents in the sexual minority group in our study were more likely to use alcohol and drugs than adolescents than their heterosexual peers. 
The absence of sexual debut on the other hand correlated positively with lower frequencies of risk behaviours as reported earlier (Sandfort et al., 2008). The adolescents and young adults with no sexual debut at 18 were less likely to smoke or use alcohol and drugs and reported significantly less antisocial behavior compared to their peers with experience of oral, vaginal or anal sex.

Clinical implications and reflexions. It is of clinical value to be aware that an early sexual debut increases risk behaviours such as not using condom when having sex, use of alcohol and drugs when having sex, unplanned pregnancies, sexual transmitted diseases and a high number of sexual partners during adolescence. I believe most clinicians working with adolescents already are aware of this since much has been written about those associations. It is also of clinical importance to be aware that an early sexual debut is associated with lower mental health, antisocial behaviours, alcohol and other drugs as found in our and other studies (Downing \& Bellis, 2009; Makenzius \& Larsson, 2012). As a psychiatrist I meet many adolescents with impaired mental health, significant antisocial behaviours and also with a high alcohol and or drug consumption. As a result of this, I have reached the conclusion that both a sexual history (including Internet and online sexual activities), an alcohol and drug history and a drug screening test should be taken at every visit at psychiatric emergency department. This should also be done at some stage during a longer contact with a psychiatric clinic as a part of the evaluation. I believe that we miss many adolescents at the beginning of an alcohol or drug career so if they could identified earlier we might have opportunities to help them to stop and prevent further suffering.

Since healthy relations with parents and stable family situations seems to postpone an early sexual debut and are protective factors against other risk behaviours it is as always of great importance and clinical value to investigate the family system among patients with an early sexual debut.

Since almost all western adolescents have access to Internet (Ofcom, 2014, Statens mediaråd, 2013) and life online and offline today is integrated, sexuality and sexual behaviours have an arena online. No specific online risk behaviour has been described as more risky than others but Ybarra et al. (2007) stressed that adolescents with a combination of different sexual behaviours online might be more at risk than others. Jonsson et al. (2015) found that adolescents displaying sexual behaviour online had poorer health, lived a more sexualized life and had more experiences of maltreatment combined with a more risk taking life in general. 
The data collection in study I was done more than 10 years ago and did not include aný questions about Internet use or online habits among the children. If we were to perform the same study today we would add those questions. In clinical practice I think it should be compulsory to ask both children and adolescents about their online activities and directly ask them to describe their current online sexual activity.

\section{Sexual debut age, sexual identity and its associations with child abuse}

We identified what earlier studies also had shown, (Dahle et al., 2010; Pedersen \& Skrondal, 1996; Reisner et al., 2014; Valle et al., 2009) namely that the age of the sexual debut and also specific kinds of sexual identity are correlated with child abuse. Experience of child abuse, meaning both physical and sexual abuse, was found to be more common among the adolescents with an early sexual debut and among the adolescents with a minority sexual identity. The girls with an early debut had nearly three times as often experience of sexual abuse than the girls with sexual debut at 14 years or later. For boys, experience of physical abuse (having been pushed or shaken, having something thrown at them, being hit with an object or a hand, being kicked, burnt or scalded) significantly increased the odds of an early sexual debut compared to boys with no such experience. The results were similar for the girls; the experience of having been pushed or shaken, being hit with a hand, been kicked and hit or bitten, were all associated with increased odds of having had an early sexual debut.

As Roberts et al. (2010) and Saewyc et al. (2006) already had reported we also found a positive correlation between belonging to a sexual minority group and experiencing both penetrating sexual abuse and physical abuse. Penetrating sexual abuse was reported by nearly one in four among these adolescents and young adults. Nearly $50 \%$ of the LGB individuals had experienced physical child abuse, compared to almost $31 \%$ of the heterosexual group.

Clinical implications and reflexions. As a clinician I know how hard it can be to recognize and identify children and adolescents with experiences of child physical abuse, sexual abuse and sexual exploitation but it is of great importance to do so. The children and adolescents with a history of child abuse do more often seek medical care than their peers without a history of abuse (Sakso \& Almroth, 2015) so we do see them in hospital or in noninstitutional care. However, for a variety of different reasons they tend not to tell anyone about the abuse (Devoe \& Faller, 1999; Leander et al., 2007; Svedin \& Back, 2003) and there 
are seldom signs on their bodies (especially when the abuse is sexual). It is an important challenge to find these children and adolescents in order to offer and provide support and if needed appropriate treatment.

In hospital or in first line psychiatry, when taking the history from an adolescent patient, it is of great importance when taking the sexual history to also include experiences of abuse and sexual exploitation. Patients at psychiatric clinics more often have an early sexual debut and my suggestion is that except for drug screening and sexual history an abuse or trauma history including questions about sexual exploitation should always be taken at every visit at psychiatric emergency department. The abuse history should also routinely be taken at visits at the first line psychiatry care as school nurses, general practice offices and at psychiatric non-institutional care.

It is also very important that professionals be aware of the fact that experience of child abuse is more common among LGB adolescents than among other groups (Reisner et al, 2014), A finding supported by our study where more than one-third of LGB individuals had the experience of penetrating sexual abuse and nearly half of them had experienced child physical abuse.

If all professionals working with children and adolescents would learn to ask these difficult but very important questions, my belief is that a larger number of abused children and adolescents would get the attention and care they deserve and need.

Sexual debut age, sexual identity and its associations with sexual exploitation

Of all the adolescents in our study, $1.5 \%$ stated that they had sold sex (displayed their genitals, been photographed or filmed, had masturbated for someone, had had oral sex, vaginal or anal intercourse or had been photographed or filmed in sexual situations for payment). Studies from other Nordic countries show similar results as $1 \%$ of youths in Denmark and $1.4 \%$ in Norway had received payment for sex (Helweg-Larsen, 2003; Pedersen $\&$ Hegna, 2003). We found that this experience was much more common among boys $(9.1 \%)$ and girls (5.8\%) in the early sexual debut group and among the adolescents in the sexual minority group (7.6\%). Even though the possibilities for selling sex have changed, notably 
since these activities have moved from the street to the Internet the number of Swedish adolescents with experience of selling sex has not increased between 2004 and 2009 (Fredlund et al., 2013).

Clinical implications and reflexions. Since the fact that $1.5 \%$ of this normal population of 18-year old adolescents in Sweden have experience of selling sex and this practice is even more common among adolescents with an early sexual debut and LGB adolescents, this should be considered a major psychosocial problem. My suggestion is that guidelines for practitioners should specify that it is as compulsory to ask about sexual exploitation, as it is to ask about the other health behaviours and traumas when seeing these adolescents in psychiatric care. It is also of great importance to develop evidence-based treatment for those who sell sex as it is a self-destructive behaviour.

\section{Methodological considerations and limitations}

An obstacle with study I was that the data were based on parents' observations and reporting and not on interviews or by directly observing the children. Behaviours reported by the parents are the ones they observe and of course do not include all elements of a child's' behaviour. There is a risk of underreporting, especially when the child grows older and has more integrity and has become socialized to not show certain behaviours, especially not sexual behaviours. Also different observers may have different levels of motivation for filing reports that are accurate and complete. Another limitation in study I is that the absolute majority of the parents who answered our questionnaire were mothers. The participation rate was $63.1 \%$ and a limitation of the study is that we do not know anything about the children or the parents that chose not to participate in the study. Another limitation is that the questionnaire did not include any questions about Internet use and sexual activities online. Children of today spend much time online and we really need to know about their sexual behaviours and activities online as well as in their ordinary daily life when offline.

There were similar problem in study II, III and VI when only 119 of the selected 150 schools responded to the request for participation or did return the questionnaires. The response rate in the school sample became $60.5 \%$, which is lower than comparable school-based Scandinavian studies (Helweg-Larsen et al, 2012). This may be explained by the fact that the 
study was conducted in the last year of high school and at the end of the school year, when it can be difficult to gather the whole class due to various year-end activities. Possibly, the sensitive content of the questions made the adolescents more unwilling to participate, or the fact that they were distributed by school staff and completed by the adolescents in the classroom. To maintain the integrity of the students, and to minimize the risk of them not answering the questions seriously, the class was optional and the students sat far away from each other. They were also informed in advance that they could elect to not take part. They were also given information about where to turn for counseling afterwards.

The questionnaire asked adolescents to define a number of concepts and one cannot assume that all individuals in a group will define a concept in the same way.

Since early onset of puberty correlates with early sexual debut (Landsford, 2010; Downing \& Bellis, 2009), it would have been very interesting to have information about age of onset of puberty, Tanner stage and menarche. Since the release of serotonin has been reported to have an inhibitory influence on sexual behavior and libido (Hull, 2011) it would have been useful to have information about use of selective serotonin reuptake inhibitors (SSRI). A well-known side effect of antidepressant SSRIs is the decrease of both sexual desire and sexual functioning (Cascade \& Kennedy, 2009). There were no questions about long-term depression or sadness, suicidal thoughts or suicide attempts which could have been useful when measuring mental health or quality of life. It would also have been interesting to ask about parental attitudes to sexual orientation of their children.

Another limitation is that this study included mostly Swedish and some Nordic and Europeanborn adolescents, but only a few born outside Europe

A limitation of the population in study IV comprised LGBs that were easy to reach, especially the RFSL members, as they were linked to a sexuality-based community and many of them had identified themselves as lesbian, gay or bisexual. As Meezan and Martin (2009) pointed out, many studies include these LGBs, but don't tend to include hard to reach subjects, such as those living in rural areas, those who are not sure about the identity, the homeless and people with mental health problems. 


\section{Ethical considerations}

As noted previously, ethical approval for these studies was gained from the Regional Ethical Review Board in Linköping Sweden (Dnr 01-418 for study I and Dnr 220-08 for study II-IV) and ethical issues were adhered into the design of the research.

It is important to consider and reflect on the ethical challenges and procedures when conducting research on a sensitive topic as sexuality and sexual behaviour and to consider the risk of harm to the participants.

Children's sexual behaviour is a sensitive subject. To participate in a study like ours may lead to questions among the parents that they have not previously thought about and that even professionals sometimes have difficulty discussing. This can create worries for the parents and can even provoke some individuals and cause them to refuse to participate in a study. In study I it would have been unethical and unreliable to approach the children directly so we turned to their parents with a questionnaire about their child's general and sexual behaviours. To minimize the risk of harm and to inform the participants in this study we wrote a letter to the parents with an explanation of the reason for the study. A few parents wrote back that they felt uncomfortable with the topic and questions and did not want to be a part of the study. It is a delicate task how to introduce the subject children's sexuality to parents and to explain in a satisfactory way that the study is not about sexuality as concerns adult sexual activities but about sexuality as a developmental process. It might have been better to have informed the parents in a more personal way, with information about the study and also to have explained more fully what we mean by "children's sexuality" in the broad sense and thereafter be available for questions.

In study II-IV we turned to adolescents and young adults with a questionnaire about health, sexual identity, sexual habits, sexual exploitation and experiences of child abuse. As researchers we had the responsibility to ensure that the data collection was handled respectfully and with special attention to the young participants and the sensitive topics in the questionnaire. Parents were not asked about their adolescent's participation since according to the Swedish Ethical Review Act, section 18, active consent from the parent is not mandatory when the adolescent is over 15 years of age (Svensk författningssamling [SFS], 2003:460). The fact that the adolescents answered the questionnaire in school and without parents 
consent also ensured that the parents did not know their children's views on these sensitive topics. The students were informed about the study in advance and were told on what date and time the survey was going to be done. They were therefore free to simply not turn up in school at that date and time. They could also choose to fill in the questionnaire or not even during the class. To assure the students integrity they were placed in a manner to ensure that no student could read the answers of surrounding students while performing the survey. The confidentiality, the freedom to decline participation, and the fact that the answers were sent back to the researchers and not to the school may have increased the willingness of students to participate despite the sensitive topics being addressed in the questionnaire.

The adolescents may have pleasurable, mutual sexual experiences but also involuntary and or coercive ones. A study like this with questions about abuse, selling sex etcetera might bring back painful memories that the adolescent might find traumatic or problematic. One way to handle this is to provide crisis line numbers or lists of resources that offer psychological counselling or therapy and to encourage the participants to seek help if needed to. We chose to give each participant a printed information leaflet about where they could turn for counselling in case they felt they needed support.

When performing research about sensitive topics such as sexual abuse and sexual exploitation eventual iatrogenic effects must be considered. Priebe, Bäckström and Ainsaar (2010) reported that a majority of adolescents who participated in data collection on sexuality said that they did not experience distress after the investigation and the same was true even for vulnerable adolescents who had experience of sexual abuse. 


\section{Suggestions for future work}

We need to be able to describe sexual behaviour among 7 to 13 year old children with known experience of sexual abuse in more specific ways that help to determine which behaviours should be counted for as "red flags". This could be done by using the same questionnaire as in study I but on children with a history of known sexual abuse. It will also be essential to add questions about Internet use and online sexual activities among schoolchildren.

Further research is also needed to explore the reasons for the high prevalence of selling sex

among the adolescents with an early sexual debut and the LGB adolescents and also to develop strategies for prevention and clinical programs or therapy for recovering. 


\section{ACKNOWLEDGEMENTS}

I wish to express my absolute gratitude to:

All the abused children I have met and meet in my clinical work. You have continuously given me the strength to work in this field.

Professor Carl Göran Svedin, my main supervisor, for sharing great scientific knowledge, constructive advice and for saying yes much more often than no.

Professor Gunilla Sydsjö, my associate supervisor, for skilful scientific support, encouraging discussions and for always quick mail replies.

Statistician Marie Bladh, for generously sharing skills, coffee and laughter.

Translators Annette Whibley and Larry Lundgren for friendly and excellent help with the English language.

All the members of Barnskyddsteamet Region Östergötland, for sharing the interest and drive to find and help abused children.

All of the staff at BUP Elefanten for extraordinary professional skills in taking care of the abused children and their families and for creating the most nourishing place to work at.

Lena Banck och Kicki Back for always sharing your knowledge and for being wise mentors in the field of child abuse.

Current and former members in the research group of Child and Adolescent Psychiatry, for support and creative discussions.

Current and former colleagues and co-workers in the Psychiatric Clinic and the Child and Adolescent Psychiatric Clinic at the University Hospital of Linköping for making it possible for me to combine clinical work with research and for all the personal interest and support.

All the staff at Akutenheten at the Psychiatric Clinic, University Hospital of Linköping for always being positive, extremely skilled and helpful and for doing very important work every day and every night.

My friends and colleagues Sara Agnafors and Linda Jonsson for taking time to read, comment and discuss my thesis. 
My parents Annette and Håkan for always believing in me and for being optimistic for nearly all of my different ideas during the years.

My wing mate and brother Alf and my spouse Lisa for scientific support in a special way but mostly for sharing everyday life as well as celebrations.

My sister Lena for sharing the fascination for psychiatry and for the company in the beginning of our careers at the Psychiatric clinic in Sundsvalls Sjukhus.

My friend and colleague Eleonor Ahlgren for being there all the time, sharing the ups and downs of life.

My friend and colleague Elizabeth Freihaut for a lifelong friendship with many plans and the most giving conversations.

My husband Per, for endless love, encouragement and excessive technical support.

My extrachildren Ebba, Nora, Beata for sharing interesting thoughts, a lot of fun and for supporting me, all in your own way.

My dear children Petronella, Jona and Leo for all the true happiness and love, for all the adventures we have had and will have and for being just the way you are. 


\section{REFERENCES}

Abela A, Büttner O, Jönsson I, Karelson K, Kutsar D, Longo V. et al. (2003). Changing family structure in Europe: new challenges for public policy (No. 5) Leicestershire: European Research Centre

Ainsworth MDS, Blehar MC, Waters E \& Wall S. (1978) Patterns of attachment: Assessed in the strange situation an at home. Hillsdale. NJ. Earlbaum

Antonovsky A. (1987) Unravelling the mystery of health. San Francisco, CA: Jossey-Bass

Argiolas A, Melis MR. (2003) The neurophysiology of the sexual cycle. Journal of Endocrinological Investigation 26(3 Suppl):20-22

Bancroft HJ. (2003) Sexual development in children. ISBN: 9780253342430 Kinsey Institute Series. Indiana University Press.

Barker RL. (1995) The social work dictionary ( $3^{\text {rd }}$ ed) Washington DC: NASW

Bauman KE \& Udry JR. (1981) Subjective expected utility and adolescent sexual behaviour. Adolescence 16:527-535

Baumgartner SE, Valkenburg PM \& Peter J. (2010) Assessing causality in the relationship between adolescents risky sexual online behaviour and their perceptions of this behaviour. Journal of Youth and Adolescence 39:1226-1239

Baumgartner SE, Sumter SR, Peter J \& Valkenburg PM. (2012) Identifying teens at risk: developmental pathways of online and offline sexual risk behaviour. Pediatrics 130:14891496 
Berg L. (2011) Hur unga blir sexuella aktörer. En kontruktionistisk förklaringsmodell. In Ungdomar, sexualitet och relationer. (How young people becomes sexual performers. A constructionistic model. In Youth, sexuality and relations.) Magnusson C \& HäggströmNordin E. (Eds) Lund: Studentlitteratur

Bergenheim A. (1994) The child, libido and society - about the Swedish discourse around child sexuality 1930-1960. Doctoral dissertation, Umeå University, Department of the History of Ideas. Höglunds förlag

Basile KC, Chen J, Black MC \& Saltzman LE. (2007) Prevalence and characteristics of sexual violence victimization among US adults, 2001-2003. Violence and Victims.22(4):437488

Belsky J, Steinberg L, Houts RM, \& Halpern-Felsher BL. (2010) The development of reproductive strategy in females: Early maternal harshness!earlier menarche!increased sexual risk taking. Developmental Psychology 46:120-128 doi:10.10370015549

Birnbaum GE. (2007) Attachment orientations, sexual functioning, and relationship satisfaction in a community sample of women. Journal of Social Personal Relationships 24:21-35

Biro FM, Huang B, Crawford PB, Lucky AW, Striegel-Moore R, Barton BA et al. (2006) Pubertal correlates in black and white girls. Journal of Peadiatrics 148:234-240

Bjerrum Nielsen H \& Rudberg M. (1991) Historien om flickor och pojkar. Könssocialisation i ett utvecklingspsykologiskt perspektiv. (The story of girls and boys. Gender-socialisation in a developmental perspective) Lund: Studentlitteratur

Bogaert AF. (2006) Toward a conceptual understanding of asexuality Review of General Psychology 10(3):241-250

Bogaert AF. (2004) Asexuality: prevalence and associated factors in a national probability sample Journal of Sex Research 41(3):279-287 doi:10.1080/00224490409552235 
Bos H, van Beusekom G \& Sandfort T. (2014) Sexual attraction and psychological adjustment in Dutch adolescents: Coping style as a mediator. Archives of Sexual Behaviour 43(8):1579-1588 doi:10.1007/s10508-014-0308

Bonner BL, Walker CE \& Berliner L. (1999) Children with sexual behavioural problems: Assessment and treatment final report. Washington DC, US Department of Health and Human Services, National Clearinghouse on Child Abuse and neglect

Bowlby J. (1965) Maternal care and mental health. In J. Bowlby (Ed.) Child care and the growth of love. London. Penguin.

Bowlby J. (1969) Attachment and loss. Vol. 1. Attachment. New York: Basic Books

Bowlby J. (1977) The making and breaking of affectional bonds. Brittish Journal of Pshyciatry 130(3):201-210

Bowlby, J. (1988) A secure base: Parent-child attachment and healthy human development. New York: Basic Books

Brilleslijper-Kater SN \& Bartman HEM. (2000) What do young children know about sex? Research on the sexual knowledge of children between the ages of 2 and 6 years. Child Abuse Review 9:166-182

Broberg A, Risholm-Mothander P, Granqvist P \& Ivarsson T. (2008) Anknytning I praktiken - tillämpning av anknytningsteorin. (Attachment in practice - applying the attachment theory) Stockholm: Natur \& Kultur

Brown LK, Danovsky MB, Lourie KJ, DiClemente RJ \& Ponton LE. (1997) Adolescents with psychiatric disorders and the risk of HIV. Journal of American Academy of Child and Adolescent Psychiatry 36:1609-1617

Bush G, Luu P \& Poser MI. (2000) Cognitive and emotional influences in anterior cingulate cortex. Trends in Cognitive Science 4(6):215-222

Bussey K \& Bandura A. (1999) Social cognitive theory of gender development and differentiation. Pschycological Review 106:676-713 
Butzer B \& Campbell L. (2008) Adult attachment, sexual satisfaction, and relationship satisfaction: A study of married couples. Personal Relationships 15:141-154

Bux DA. (1996) The epidemiology of problem drinking in gay men and lesbians: A critical review. Clinical Psychology Review 16:277-298

Caplan P. (1987) The cultural construction of sexuality. London. Routledge.

Cascade E Kalali AH \& Kennedy SH. (2009) Real-world data on SSRI antidepressant side effects. Psychiatry (Edgmont) 6(2):16

Casteel K \& Mallants C. (2008) Practical approach to Childhood masturbation - a review. Journal of Pediatric 10:1111-1117

Cavanagh Johnson T \& Friend C. (1995) Asssessing young children's sexual behaviours in the context of child abuse evaluations. In True and false allegations of child sexual abuse: assessment and case management. Ed Ney T. New York: Brunner/Mazer, Inc

Cavazos-Rehg PA, Spitznagel EL, Bucholz KK, Nurnberger JJr, Edenberg HJ, Kramer JR et al. (2010) Predictors of sexual debut at age 16 or younger. Archives of sexual behaviour 39(3):664-673

Chen LP, Murad MH, Paras ML, Colbenson KM, Sattler AL, Goranson EN, Elamin MB, Seime RJ, Shinozaki G, Prokop LJ \& Zirakzadeh. (2010) Sexual abuse and lifetime diagnosis of psychiatric disorders: systematic review and meta-analysis. Mayo Clinic Proceedings. 85(7):618-629

Collier KL, Horn SS, Bos HM, Sandfort TG. (2014) Attitudes toward lesbians and gays among American and Dutch adolescents. Journal of Sexual Research 52(2):140-150

Compian L, Gowen LK \& Hayward C. (2004) Peripubertal girls'romantic and platonic involvement with boys: Associations with body image and depression symptoms. Journal of Research on Adolescence 14:23-47

Cooper A. (1998) Sexuality and the Internet: surfing into a new millennium. Cyberpsychology Behaviour 1:187-193 
Cooper A \& Griffin-Shelly E. (2002) The Internet: The new sexual revolution. In Cooper A. (Ed) Sex and the Internet: A guidebook for clinicians. 1-15 New York: Brunner. Rutledge

Cornelius JR, Clark DB, Reynolds M, Kirisci L \& Tarter R. (2007) Early age of first sexual intercourse and affiliation with deviant peers predict development of SUD: A prospective longitudinal study. Addictive Behaviours 32:850-854

Crocett LJ, Rafaelli M \& Moilanen KL (2003) Adolescent sexuality: behavior and meaning. In GR Aams \& MD Berzonsky (Eds) Bleckwell handbook of adolescence (pp 371-392) MA Malden: Bleckwell Publishing Ltd.

Cunningham S \& Kendall TD. (2011) Prostitution 2.0. The changing face of sex work. Journal of Urban Economics 69:273-287

Dahan R, Feldman R, Hermoni D. (2007) The importance of sexual orientation in the medical consultation. Harefuah 146(8):626-630

Dahle T, Dalen HA, Meland E \& Breidablik HJ. (2010) Unwanted sexual experience and health complaints among adolescents. Tidsskrift for den Norske Legeforening. 7 130(19):1912-1916

Daneback K \& Månsson SA. (2009) Kärlek och sexualitet på Internet 2009. I Ungdomsstyrelsen 2009:9 (Ed) Se mig. Unga om sex och Internet. (Love and sexuality on the Internet 2009. In the Swedish National Board for Youth affairs. 2009:9 (Ed) See me. Young People on sex and the Internet) 182-237 Stockholm: Ungdomsstyrelsen

Davis D, Shaver PR \& Vernon ML. (2004) Attachment style and subjective motivations for sex. Personality and social psychology bulletin.(30):1076-1090

Davies SL, Glaser D \& Kossoff R. (2000) Children's sexual play and behaviour in pre-school settings: Staff's perceptions, reports and responses. Child Abuse \& Neglect 24(10):1329-1343 
Deblinger E, McLeer SV, Atkins MS, Ralphe D \& Foa E. (1998) Posttraumatic stress in sexually abused, physically abused and nonabused children. Child Abuse \& Neglect 13:404408

De Genna NM, Larkby C \& Cornelius MD. (2011) Pubertal timing and early intercourse in the offspring of teenage mothers. Journal of Youth and Adolescence 40(10):1315-28

De Graaf H \& Rademakers J. (2006) Sexual behaviour of prepubertal children. Journal of Psychology \& Human Sexuality 18:1-21

De Graaf H \& Rademakers J. (2011) The psychological measurement of sexual development in western societies: Methodological challenges. Journal of Sex Research 48(2-3):118-129

Derogatis LR. (1977) SCL-90. Administration, scoring and procedures manual-I for the revised verion. John Hopkins University School of Medicine. Baltimore

Diamond D, Blatt SJ, Lichtenberg JD. (2007) Attachment and sexuality. New York: The Analytic Press/Taylor \& Francis Group

Donders GGG, Folens S, Peperstraete B \& Bellen G. (2011) Age of sexual debut and central introital dyspareunis. European Journal of Obstetrics \& Gynecology and Reproductive Biology 158:90-92, doi:10.1016/j.ejogrb.2011.04.016

Donenberg G, Wilson H, Emerson E \& Bryant F. (2002) Holding the line with a watchful eye: the impact of perceived parental monitoring and parental permissiveness on risky sexual behavior among adolescents in psychiatric care. AIDS Education and Prevention 14:138-157

Donenberg GR, Emerson E, Bryant FB, Wilson H \& Weber-Shifrin E. (2001) Understanding AIDS-risk behavior among adolescents in psychiatric care: links to psychopathology and peer relationships. Journal of American Academy of Child and Adolescent Psychiatry 40:642-653

DeLamater J \& Friedrich WN (2002) Human sexual development. The Journal of sex Research 39(1):10-14 
Derogatis LR. (1977) SCL-90. Administration, scoring and procedures manual-I for the R(e)vised version. John Hopkins University School of Medicine, Baltimore.

Downing J \& Bellis MA. (2009) Early pubertal onset and its relationship with sexual risktaking, substance use and anti-social behaviour: a preliminary cross sectional study. $B M C$ Public Health Dec 3;9:446 doi: 10.1186/1471-2458-9-446

Döring NM. (2009) The Internet's impact of sexuality: A critical review of 15 years of research. Computers in Human Behaviour 25:1089-1101

Eaton DK, Kann L, Kinchen S, Ross J, Hawkins J, Harris WA, Lowry R, Mc Manus T, Chyen D, Lim C, Brener ND \& Wechsler H. (2008) Youth risk behaviour surveillance United States Morbidity and Mortality Weekly Report 57(4):1-131

Edgardh K, Lewin B \& Nilsson BR. (1999) Sexual experience and behaviouras reported by 17-year-old girls and boys in Sweden. Scandinavian Journal of Sexology 12:41-60

Edwards LM, Haglund K, Fehring RJ \& Pruszynski J.(2011) Religiosity and sexual risk behaviours among Latina adolescents: trends from 1995 to 2008. Journal of Womens Health 20(6):871-877

Ehrhardt AA. (1996) Our view of adolescent sexuality: A focus on risk behaviour without the developmental context. American Journal of Public Health 86:1523-1525

Eisenberger NI, Lieberman MD \& Kipling WD. (2003) Does rejection hurt? An fMRI study of social exclusion. Science 302(1126):290-292 doi:10.1126/science.1089134

Eric W, Owens EW, Richard J, Behun RJ, Jill C, Manning JC \& Rory C. (2012) The impact of internet pornography on adolescents: a review of the research. Sexual Addiction and Compulsivity: The Journal of Treatment \& Prevention 19:99-122

Eriksson EH. (1980) Identity and the life cycle. New York. Norton

Eriksson M \& Lindström B. (2005). Validity of Antonovsky’s sense of coherence scale: a systematic review. Journal of Epidemiology and Community Health 59:460-466 
Finer LB. Trends in premarital sex in the United States, 1954-2003. (2007) Public Health Report 122:73-78

Fine M. (1988) Sexuality, schooling, and adolescent females: The missing disclosure of desire. Harvard Educational Review 58:29-53

Finkel ML \& Finkel DG. (1981) Sexual and contraceptive knowledge, attitude and behavior of male adolescents. In F Furstenberg, R Lincoln \& J Menken (Eds) Teenage sexuality, pregnancy and childbearing Philadelphia: Temple University Press

Finkelhor D. (1979) Sexually victimized children. New York: Free press

Finkelhor D. (1983) Childhood sexual experiences: A retrospective survey. Family Research Laboratory. University of New Hampshire, Durham

Foucault M. (1980) Sexualitetens historia I. Viljan att veta. (The history of sexuality. The will to knowledge.) Stockholm. Gidlunds

Fredlund C, Svensson F, Svedin CG, Priebe G \& Wadsby M. (2013) Adolescents' lifetime experiences of selling sex. Development over five years. Journal of Child Sexual Abuse 22(3):312-325

Friedrich W. (1991) Sexual behaviour in sexually abused children. In Briere (Ed) Treating victims of child abuse. San Fransico: Jossey-Bass

Friedrich WN, Grambsch P, Broughton D, Kuiper J \& Beilke RL. (1991) Normative sexual behaviour in children. Pediatrics $88: 456-464$

Friedrich WN, Grambsch P, Damon L, Hewitt SK, Koverola C. et al. (1992) Child sexual behaviour inventory: normative and clinical comparisons. Psychological Assessments 4:303311 
Friedrich WN. (1997) CSBI. Child Sexual Behavior Inventory: Professional Manual. US. Rochester: Mayo Clinic Foundation.

Friedrich WN, Fisher J, Broughton D, Houston M \& Shafran CR. (1998) Normative sexual behaviour in children: a contemporary sample. Pediatrics 101(4):e9

Friedrich WN. \& Lane ST. (2002) Sexual behaviour in children across multiple settings. Child Abuse and Neglect 26:243-245

Furman W, Simon VA, Shaffer L \& Bouchey HA. (2002) Adolescents' working models and styles for relationships with parents, friends and romantic partners. Child Development (73):241-255

Gagnon J \& Simon W. (1973) Sexual Conduct: The social sources of human sexuality. Chicago: Aldine Publishing Company

Galenson E. (1990) Observation of early infantile sexual and erotic development. In Perry ME. (Ed) Handbook of sexuality Vol.7: Childhood and Adolescent sexology. Amsterdam: The Nederlands: Elsevier

Gathorne-Hardy J. (2000) Sex the measure of all things. A life of Alfred C Kinsey. Bloomington: Indiana University Press

Gil E \& Cavanagh Johnson T. (1993) Sexualized children-assessment and treatment of sexualized children and children who molest. United States: Launch Press

Goldberg RE. (2012) Family instability and early initiation of sexual activity in Western Kenya. Demography 50(2):725-750 doi. 10.1007/s13524-012-0150-8

Goldberg S, Muir R \& Kerr J. (1995) Attachment theory: Social, developmental and clinical perspectives. Hillsdale NJ: Analytic Press

Goldman R \& Goldman J. (1982) Children's sexual thinking. London: Routledge and Kegan Paul 
Goodman R. (2001) Psychometric properties of the strengths and difficulties questionnaire. Journal of the American Academy of Child and Adolescent Psychiatry 40(11):1337-1345

Gordon BN, Schroeder CS \& Abrams JM. (1990) Age and social-class differences in children's knowledge of sexuality. Journal of Clinical Child Psychology 1:33-43

Grady ES, Humfleet GL, Delucchi KL, Reus VI, Munos RF \& Hall SM. (2014) Smoking cessation outcomes among sexual and gender minority and nonminority smokers in extended smoking treatment. Nicotine \& Tobac Research 16(9):1207-1215

Green KE \& Feinstein BA. (2012) Substance use in lesbian, gay and bisexual populations: an update on empirical research and implications for treatment. Psychological Addictive Behaviour 26(2):265-278

Haglund KA \& Ferring RJ. (2010) The association of religiosity, sexual education, and parental factors with risky sexual behaviours among adolescents and young adults. Journal of Religion \& Health. 49(4):460-472

Hansson K \& Cederblad M. (1995). Känsla av sammanhang. Studier från ett salutogent perspektiv (Sense of Coherence. Studies from a salutogenic perspective). Lund University. Department of Child and Adolescent Psychiatry, Lund

Harden PK. (2011) True love waits? A sibling-comparison study of age at first sexual intercourse and romantic relations in young adulthood. Psychological Science 23(11):13241336 doi:10.1177/0956797612442550

Hatzenbuehler ML, Bellatorre A, Lee Y, Finch BK, Muennig P \& Fiscella K. (2014) Structural stigma and all-cause mortality in sexual minority populations. Social Science \& Medicine 103:33-41

Haugaard JJ. (1996) Sexual behaviours between children: professionals’́ opinions and undergraduates'recollections. Families in society. Journal of Contemporary Social Services 2:81-89

Hbtq och Idrott. Ungdommars erferenheter och villkor inom Svensk Idrott. (2013) Darj F, Piehl M \& Hjelte F. Fou Rapport 2013:1 
Helweg-Larsen K, Schütt N \& Larsen HB. (2012) Predictors and protective factors for adolescent Internet victimization: Results from a nationwide Danish youth survey. Acta Paediatrica 101:533-539

Heiman ML, Leiblum S, Cohen Esquilin S \& Mellendez Pallitto L. (1998) A comparative survey of beliefs about "normal" childhood sexual behaviour. Child Abuse \& Neglect. 22:289304

Helmius G. (1990) Mogen för sex? Det restriktiverande samhället och ungdomars heterosexualla glädje. (Mature for sex? The restrictive society and young heterosexual joy.) Uppsala: Sociologiska Institutionen

Helweg-Larsen K. (2003) Undersogelse "Hvad vi ikke ved om born og unge" (What we donot know about children and youth) Paper presented at the $7^{\text {th }}$ Nordiske Prostututionskonferences.

Herlitz CA \& Ramstedt K. (2005) Assessment of sexual behaviour, sexual attitudes, and sexual risk in Sweden (1989-2003) Archives of Sexual Behaviour 35(2):219-229

Hobsbawm E. Age of extremes: The short twentieth century 1944-1991. London, Little Brown

Horwitz VA. (2007) Transforming Normality into Pathology: The DSM and the Outcomes of Stressful Social Arrangements". Journal of Health and Social Behaviour 48:211-222 doi:10.1177/002214650704800301.

Hull EM, Muschamp JW \& Sato S. (2004) Dopamine and serotonin: influences on male sexual behavior. Physiology \& Behaviour 15;83(2):291-307

Hull EM. (2011) Sex, drugs and gluttony: how the brain controls motivated behaviors. Physiology \& Behaviour 25;104(1):173-177

Hulter B. (2004) Sexuell hälsa. (Sexual health). Lund: Studentlitteratur 
Häggström-Nordin E. (2009) Ungdomars sexualvanor. (Sexual habits among youth) In Ungdomar, sexualitet och relationer. (Youth, sexuality and relations) Magnusson C \& Häggström-Nordin E. (Eds). Lund: Studentlitteratur

Häggström-Nordin E, Hansson U \& Tydén T. (2002) Sex behaviour among high school students in Sweden: improvement in contraceptive use over time. Journal of Adolescent Health. 30(4):288-295

Häggström-Nordin E, Hansson U \& Tydén T. (2005) Associations between pornography consumption and sexual practices among adolescents. International Journal of STD \& AIDS (16):102-107

Jackson S. (1982) Childhood and Sexuality. Oxford: Basil Blackwell

Johansson T \& Ritzén ME. (2005) Very long-term follow-up of girls with early and late menarche. Endocrine development 8:126-136

Johnson TC. (2009) Helping children with sexual problems: a guidebook for professionals and caregivers. 4th edition. Family Violence and Sexual Assault Institute, San Diego.

Jones RK \& Biddlecom AE. (2011) The more things change...the relative importance of the internet as a source of contraceptive information for teens. Sexuality Research \& Social Policy 8(1):27-37

Jonsson LS, Priebe G, Bladh M \& Svedin CG. (2014) Voluntary sexual exposure online among Swedish youth - social background, Internet behaviour and psychosocial health. Computers in Human Behaviour 30:181-189 doi:10.1016/j.chb.2013.08.00

Jonsson LS, Priebe G, Bladh M \& Svedin CG. (2015) Online sexual behaviours among Swedish youth - Associations to background factors, behaviours and abuse. European Child \& Adolescent Psychiatry 24(10):1245-1260 doi:10.1007/s00787-015-0673-9 
Jonsson L, Cooper K, Quayle E, Svedin CG \& Hervy K. (2015) Young people who produce and send nude images: context, motivations and consequences. http://www.spirto.health.ed.ac.uk/download/website_files/SPIRTO

Kastbom AA, Sydsjo G, Bladh M, Priebe G, Svedin CG. (2015) Sexual debut before the age of 14 leads to poorer psychosocial health and risky behavior later in life. Acta Peadiatrica 104(1):91-100 doi: 10.1111/apa.12803

Kastbom AA, Sydsjo G, Bladh M, Priebe G \& Svedin CG. (2015) School-based survey of Swedish 18-year-olds shows that those who have not had sex by that age are more stable and cautious than peers. Adolescent Health, Medicine and Therapeutics in press

Kellogg ND. (2009) Clinical Report. The evaluation of sexual behaviours in children. Pediatrics 124:992-998

Kelly GF. (2004) Chapter 12 Sexuality Today: The Human Perspective (7 Ed.) McGraw-Hill Kendall-Tackett KA, Williams LM \& Finkelhor D. (1993) Impact of sexual abuse on children: a review and synthesis of recent empirical studies. Psychology Bulletin 113:164-180

Kessler S \& McKenna W. (1978) Gender: An ethnometodological approach. Chicago: The University of Chicago press.

King SA. (1999) Internet gambling and pornography: illustrative examples of the psychosocial consequences of communication anarchy. Cyberpsychology behaviour 2:175193

Kinsman SB, Romer D, Furstenberg FF \& Schwarz DF. (1998) Early sexual initiation: the role of peer norms. Pediatrics 102:1185-1192

Klettke B, Hallford DJ \& Mellor D. (2014) Sexting prevalence and correlates: A systematic literature review. Clinical Psychology Review 34:44-53 
Kuyper L \& Fokkema T. (2011) Minority stress and mental health among Dutch LGBs: examination of differences between sex and sexual orientation. Journal of Counseling Psychology 58(2):222-233

La Greca AM \& Harrison HW. (2005) Adolescent peer relations, friendships and romantic relationships: Do they predict social anxiety and depression? Journal of Clinical Child and Adolescent psychology 34(1):49-61

Lamb S \& Coakley M. (1993) "Normal” childhood sexual play and games: Differentiating play from abuse. Child Abuse and Neglect 17:515-526

Lammers C, Ireland M, Resnick M \& Blum R. (2000) Influences on Adolescents'́decision to postpone onset of sexual intercourse: a survival analysis of virginity among youths aged 13 to 18 years. Journal of Adolescent Health 26:42-48

Lansford JE, Yu T, Erath S, Pettit GS, Bates JE \& Dodge KA. (2010) Developmental precursors of number of sexual partners from age 16 to 22. Journal of Research on Adolescence 20(3):651-677

Lavoie F, Thibodeau C, Gagné MH \& Herbert M. (2010) Buying and selling sex in Québec adolescents: a study of risk and protective factors. Archives of sexual behaviour 39:1147-1160

Larsson I, Svedin CG \& Friedrich WN. (2000) Differences and similarities in sexual behavior among pre-schoolers in Sweden and in the USA. Nordic Journal of Psychiatry 54:251-257

Larsson I \& Svedin CG. (2001) Sexual behavior in Swedish preschool children, as observed by their parents. Acta Paediatrica 90:436-444

Larsson I, Svedin CG. (2002) Teacher's and parent's reports on 3- to 6-year-old children's sexual behavior - a comparison. Child Abuse \& Neglect 26:247-266

Laumann EO, Gagnon JH, Michael RT, Michaels S. (1994) The social organization of sexuality: Sexual practices in the United States. Chicago: University of Chicago Press. 
Leander L, Christianson SÅ \& Granhag PA. (2007) A sexual case study Childern's memories and reports. Psychiatry, Psychology and Law 19(2):184-179

Leung AKC \& Robson WLM. (1993) Childhood masturbation. Clinical Pediatrics 32:238241.

Lewin B. (2008) Promoting changes in existing social attitudes to women and sexuality. Tidsskrift for Norsk Psykologforening 45(6):748-753

Lewin B \& Helmius G. (1983) Ungdomar, kärlek \& sex. Om ungas sexuella liv på 80-talet. (Adolescents, love \& sex. The sex life of young people in the 1980.) Stockholm: Nordstedts

Lewin B, Fugl-Meyer K, Helmius G, Lalos A \& Månsson SA. (1998) Sex i Sverige: Om sexuallivet I Sverige 1996. (Sex in Sweden: About the sexlife in Sweden in 1996) Folkhälsoinstitutet 1998:11

Lindblad F, Gustafsson PA, Larsson I \& Lundin B. (1995) Pre-Schoolers'sexual behaviour at day-care centres: an epidemiological study. Child Abuse \& Neglect 19:569-577

Lopez Sanchez F, Del Campo A \& Guijo V. (2002) Prepubertal sexuality. Sexologies 11:4958

Mattebo M, Tydén T, Häggström-Nordin E, Nilson KW \& Larsson M. (2013) Pornography consumption, sexual experiences, lifestyles and self-rated health among male adolescents in Sweden. Journal of Developmental \& Behavioral Pediatrics 34:460-468

Makenzius M \& Larsson M. (2012) Early onset of sexual intercourse is an indicator for hazardous lifestyle and problematic life situation. Scandinavian Journal of Caring Science 27(1):20-26

Main M \& Solomon J. (1990) Procedures for identifying infants as disorganized/disoriented during the Ainsworth strange situation. In Greenberg et al. Attachment in the pre-school years: Theory, research and intervention (121-160) Chicago. University of Chicago press 
Martinson FM. (1994) The Sexual life of Children. Westport, CO: Bergin \& Gervey

Martinez G, Copen CE \& Abma JC. (2011) Teenagers in the United States: Sexual activity, contraceptive use and childbearing, 2006-2010 National Survey of family growth. National center for Health statistics

Mayer KH, Garofalo R \& Makadon HJ. (2014) Promoting the successful development of sexual and gender minority youths. American Journal of Public Health 104(6):976-981

McKenna KYA \& Bargh JA. (1998) Coming out in the age of internet: identity demarginalization from virtual group participation. Journal of Personality and Social Psychology 75: 681-694

Meier AM. (2007) Adolescent first sex and subsequent mental health. American Journal of Sociology 112:1811-1847

Meezan W \& Martin JI. (2009) Exploring current themes in research on gay, lesbian, bisexual and transgender populations (Eds) Research methods with gay, lesbian, bisexual and transgender populations. New York: Harrington Park Press

Mikulincer M \& Goodman GS. (2006) Dynamics of romantic love: Attachment, caregiving, and sex. New York: Guilford Press

Mikulincer M \& Shaver PR. (2003) The attachment behavioral system in adulthood: Activation, psychodynamics, and interpersonal processes. In: Zanna MP. (Ed) Advances in experimental social psychology. Vol. 35. San Diego, CA: Elsevier Academic Press

Miller BC \& Benson B. (1999) Romantic and sexual relationships in Adolescence. In Furman W. (Ed) The Development of Romantic Relationships in Adolescence. Cambridge: University Press

Moran JP. (2000) Teaching sex: The shaping of adolescence in the twentieth century. Cambrigde, MA: Harvard University Press 
Mustanski B, Lyons T \& Garcia SC. (2011) Internet use and sexual health of young men who have sex with men. A mixed-method study. Archives of Sexual Behaviour 40:289-300

Nettelbladt P, Hansson L, Stefansson CG, Borgqvist L \& Nordström G. (1993). Test characteristics of the Hopkins Symptom Check List-25 (HSCL-25) in Sweden, using the Present State Examination (PSE-9) as a caseness criterium. Social Psychiatry and Psychiatric Epidemiology 28:130-133

Ofcom (2014) The communications market report. Retrieved from http://stakeholders.ofcom.org.uk/binaries/research/cmr14/2014 UK CMR.pdf

O’Hara RE, Gibbons FX, Gerrard M, Li Z \& Sargent JD. (2012) Greater exposure to sexual content in popular movies predicts earlier sexual debut and increased sexual risk taking. Psychological Science 1.23(9):984-993

Okazaki S. (2002) Influences of culture on Asian Americans'sexuality. Journal of Sex Research 39:269-292

Ott MA \& Pfieffer EJ. (2009)"That's nasty to Curiosity: Early Adolescents Cognitions about Sexual Abstinence. Journal of Adolescence and Health 44:575-581

Palfrey J \& Grasser U. (2008) Born digital. Understanding the first generation of digital natives. Philadelphia: Basic Books

Paolucci EO, Genius ML \& Violato CA. (2001) Meta-analysis of the published research on the effects of child abuse. Journal of Psychology 35:17-36

Paras ML, Murad MH, Chen LP, Goranson EN, Sattler AL, Colbenson KM, Elamin MB, Prokop LJ \& Zirakzadeh A. (2009) Sexual abuse and lifetime diagnosis of somatic disorders. A systematic review and meta-analysis. JAMA 302(5):550-561

Parker G. (1983) Parental overprotection. New York: Grune \& Stratton 
Patton CG \& Viner R. (2007) Pubertal transitions in health. Lancet 369:1130-1139

Payne DL, Lonsway KA \& Fitzgerald LF. (1999) Rape myth acceptance: exploration of its structure and its measurement using the Illinois rape myth acceptance scale. Journal of Research in Personality 33(1):27-68

Pedersen W \& Kristiansen HW. (2008) Homosexual experience, desire and identity among young adults. Journal of Homosexuality.54:68-102

Pedersen W \& Skrondal A. (1996) Alcohol and sexual victimization: a longitudinal study of Norweigan girls. Addiction 91(4):565-581

Perkins AB, Becker JV, Tehee M \& Mackelprang E. (2014) Sexting behaviours among collage students: Cause of concern? International Journal of Sexual health 26(2):79-92

Peterson-Lyer K. (2013) Mobile porn? Teenage sexting and justice for woman. Journal of the society of Christian ethics 33(2)

Petersen AC, Crockett L, Richards M \& Boxer A. (1998) A self-report measure of pubertal status: reliability, validity and initial norms. Journal of Youth and Adolescence 17:117-133

Pew Research Centre (2013) Teens, social media and privacy. Retrieved from http://www.pewinternet.org/files/2013/05/PIP_TeensSocialmediaandPrivacy_PDF.pdf

Phipps-Yonas S, Yonas A, Turner M \& Kauper M. (1993) Sexuality in early childhood. University of Minnesota. Center for Urban and Regional Affairs Reporter 23:1-5

Prause N \& Graham CA. (2004) Asexuality: Classification and Characterization "Archives of Sexual Behavior 36(3):341-356 doi:10.1007/s10508-006-9142-3

Prensky M. (2001) Digital natives, digital immigrants part 1, From On the horizon. MCB University Press 9(5):1-6 
Price MN \& Hyde JS. (2009) When two isn't better than one: predictors of early sexual activity in adolescents using a cumulative risk model. Journal of Youth Adolescence 38(8): 1059-1071

Priebe G, Bäckström M \& Ainsaar M (2010) Vulnerable adolescent participants' experience in surveys on sexuality and sexual abuse: Ethical aspects. Child Abuse \& Neglect 36:438-447

Priebe G \& Svedin CG. (2009) Prevalence, characteristics and associations of sexual abuse with sociodemographics and consensual sex in a population-based sample of Swedish adolescents. Journal of Sexual Abuse 18:19-39

Priebe G \& Svedin CG. (2013) Operationalization of three dimensions of sexual orientation in a national survey of late adolescents. Journal of sex research 50(8):727-738

Proposition 2007/08:110. En förnyad folkhälsopolitik (A renewed Public Health Policy). Retrieved from http://www.regeringen.se/content/1/c6/10/09/78/2ee01484.pdf

Rademakers J, Laan M \& Straver CJ. (2000) Studing children's sexuality from the child's perspective. Journal of Psychology \& Human Sexuality 1-2:49-60

Rainville P, Duncan GH, Price DD, Benoit CM \& Bushnell MC. (1997) Pain affect encoded in human anterior cingulated but not somatosensory cortex. Science 277(5328):968-971

Ramrakha S, Bell ML, Paul C, Dickson N, Moffitt T \& Caspi A. (2007) Childhood behaviour problems linked to sexual risk taking in young adulthood: a birth cohort study. Journal of the American Academy of Child \& Adolescent Psychiatry 46(10):1272-1279

Reisner SL, White JM, Bradford JB \& Mimiaga MJ. (2014) Transgender Health disparities: comparing full cohort and nested matched-pair study design in a community health center. LGBT Health 1(3):177-184

Reyna VF \& Farley F. (2006) Risk and rationality in adolescent decision-making: Implication for theory, practice and public policy. Psychological Science in the Public Interest 7(1):1-44 
Reynolds MA, Herbenick DL. \& Bancroft J. (2003) The nature of childhood sexual experiences. J Bancroft (ed) Sexual development in childhood. 134-155

Bloomington: Indiana University Press.

RFSLs Kommunundersökning 2015. Retrieved from

www.rfsl.se/public/rfsl.kommun.2015.web.pdf

Rice E, Winetrobe H, Rhoades H, Plant A, Montoya J \& Kordics T. (2014) Sexting and sexual behaviour among middle school students. Pediatrics 134(1) e21-28

Roberts AL, Austin SB, Corliss HL, Vandermorris AK \& Koenen KC. (2010) Pervasive trauma exposure among US sexual orientation minority adults and risk of posttraumatic stress disorder. American Journal of Public Health 100:2433-2441

Rosario M, Schrimshaw EW, Hunter J \& Braun L. (2006) Sexual identity development among gay, lesbian, and bisexual youths: Consistency and change over time. Journal of Sex Research 43:46-58

Rosario M, Reisner SL, Corliss HL, Wypij D, Frazier AL \& Austin SB. (2014) Disparities in depressive distress by sexual orientation in emerging adults: the roles of attachment and stress paradigms. Archives of Sexual Behaviour 43(5):901-916

Rosenberg M. (1989) Society and the Adolescent self-image. Middleton: Wesleyan University Press

Rogala C \& Tydén T. (2003) Does pornography influence young woman's sexual behaviour? Woman's Health Issues 13:39-43

Russell ST \& Joyner K. (2001) Adolescent sexual orientation and suicide risk: evidence from a national study. American Journal of Public Health 91:1276-1281

Rutter M \& Giller H. (1984) Juvenile delinquency. Trends and perspectives. New York: The Guilford Press 
Ryan C, Huebner D, Diaz RM \& Sanchez J. (2009) Family rejection as a predictor of negative outcomes in white and Latino lesbian, gay and bisexual young adults. Pediatrics 123:346-352 Saewyc EM, Skay CL, Pettingell SL et al. (2006) Hazards of stigma: The sexual and physical abuse of gay, lesbian, and bisexual adolescents in the United States and Canada. Child Welfare 85:195-213

Sakso T \& Almroth L. Barn i Barnahus - Sjukvårdssökande före, under och efter barnahusärende. (Children at Childrens Advocacy Center. Seeking health care before, during and after Childrens' Advocacy Center.) In manuscript.

Sandfort TGM \& Cohen-Kettenis PT. (2000) Sexual behaviour in Dutch and Belgian children as observed by their mothers. Journal of Psychology and Human sexuality 12:105-115

Sandfort TGM, Orr M, Hirsch JS \& Santelli J. (2008) Long-term health correlates of sexual debut: results from a national US study. American Journal of Public Health. 98(1):155-161 doi: 10.2105/AJPH.2006.097444

Satterfield S. (1975) Common sexual problems of children and adolescents. Pediatric Clinic of North America 22:643-652

Savin-Williams RC. (2005) The new gay teenager. Cambridge, MA: Harvard University Press

Savin-Williams RC \& Diamond LM. (2000) Sexual identity trajectories among sexual minority youth: Gender comparisons. Archives of Sexual Behaviour 29(6):607-627

Sawamoto N et al. (2000) Exception of pain enhances responses to nonpainful somatosensory stimulation in the anterior cingulated cortex and parietal operculum/posterior insula: an eventrelated functional magnetic resonance imaging study. The Journal of Neuroscience 20(19):7438-7445 
Scharff DE. (2010) How development structures relationships. In: Levine SB, Risen CB, Althof SE. (Eds) Handbook of clinical sexuality for mental health professionals. 2nd edition. New York: Routledge/Taylor \& Francis Group

Schechter MD \& Roberge L. (1976) Sexual exploitation. In: Helfer RE \& Kempe CH. (Eds) Child Abuse and Neglect: The Family and the Community. Ballinger: Cambridge Massachusetts

Schoentjes E, Deboutte D \& Friedrich W. (1999) Child sexual behaviour Inventory: A Dutchspeaking normative sample. Pediatrics 104:885-893

Schuhrke B. (2000) Young children's curiosity about other people's genitals. Journal of Psychology \& Human sexuality 12:27-48

Siegel DM, Aten MJ \& Roghmann KJ. (1998) Self reported honesty among middle and high school students responding to a sexual behaviour questionnaire. Journal of Adolescent Health 23:20-28

Silovsky JF \& Bonner BL. (2003) Sexual behaviour problems. In Ollendick TH \& Schroeder CS (Eds) Encyclopedia of clinical and pediatric psychology. New York. Kluwer Press.

Silovsky JF \& Niec L. (2002) Characteristics of young children with sexual behavior problems: a pilot study. Child Maltreatment 7:187-197

Skolverket. (2014) Retrieved from www.skolverket.se

Smedje H, Broman J-E, Hetta J \& Knorring A-L. (1999) Psycometric properties of a Swedish version of the "Strength and Difficulties Questionnaire". European Child and Adolescent Psychiatry 8:63-70

Social Watch (2013) The 2012 Gender Equity Index. Retrieved from http://www.socialwatch.org/node/14367 
Sorbring E, Skoog T \& Bohlin M. (2014) Adolescent girls'and boys'well-being in relation to online and offline sexual and romantic activity. Cyberpsychology: Journal of Psychosocial Research on Cyberspace 8(1) art7

Spittal MJ, Fedyszyn I, Middleton A, et al. (2015) Frequent callers to crisis helplines: Who are they and why do they call? Australian \& New Zealand Journal of Psychiatry 49(1):54-64

Stefanou C \& McCabe MP. (2012) Adult Attachment and Sexual Functioning: A Review of Past Research. The Journal of Sexual Medicine 9(10):2499-2507

Steinberg L. (2001) We know some things. Parent-adolescent relationship in retrospect and prospect. Journal of Research on Adolescence 11(1):1-19

Starks TJ, Newcomb ME \& Mustanski B. (2015) A longitudinal study of interpersonal relationships among lesbian, gay and bisexual adolescents and young adults: meditational pathways from attachment to romantic relationship quality. Archives of sexual behaviour doi.10.1007/s10508-015-0492-6

Statens medieråd (2013) Unga \& Medier 2012/2013. Fakta om barns och ungas användning och upplevelser av medier. Retrieved from http://www.statensmedierad.se/upload/_ungar_och_medier_2013_fullfarg.pdf

Stoltenborgh M, van Ijzendoorn MH, Euser EM \& Bakermans-Kranenburg MJ. (2011) A global perspective on child sexual abuse: Meta-analysis of prevalence around the world. Child Maltreatment. 16:79-101

Strand BH, Dalgard OS, Tambs K \& Rognerud M. (2003) Measuring the mental health status of the Norwegian population: a comparison of the instruments SCL-25, SCL-10, SCL-5 and MHI-5 (SF-36). Nordic Journal of Psychiatry 57:113-118

Svedin CG \& Back C. (2003) Varför berättar dom inte? (Why don’t they tell us?) Stockholm: Rädda Barnen 
Svedin CG \& Priebe G. (2009) Unga, sex och internet, Ungdomsstyrelsen 2009:9 (Ed) Se mig. Unga om sex och internet. (Young persons, sex and the internet. In Swedish national board for Youth affairs. See me. Young people on sex and internet) 32-143 Stockholm: Ungdomssyrelsen

Svensk författningssamling (2003:460) Lagen om etikprövning av forskning som avser människor. Stockholm: Utbildningsdepartementet

Svensson F, Fredlund C, Svedin CG, Priebe G \& Wadsby M. (2013) Adolescents selling sex: Exposure to abuse, mental health, self-harm behaviour and the need for help and support-a study of a Swedish national sample. Nordic Journal of Psychiatry 67(2)81-88

Suzuki LK \& Calzo JP. (2004) The search for peer advice in cyberspace: An example of online teen bulletin boards about health and sexuality. Journal of Applied Developmental Psychology 25:685-698

Sörensen DA. (2007) Porno-chic -sex and mainstreaming of pornography in massculture. In Generation P? Youth, gender and pornography. Ed Knudsen VS et al. Köpenhamn: Danmarks Pedagogiske Universitetsforlag

Tanner JM (1967) Puberty. In A. McLaren (Ed.) Advances in reproductive physiology (Vol. II) New York: Academic Press

Thigpen JW. (2009) Early sexual behaviour in a sample of low-income, African American Children. Journal of Sex Research 46:67-79

Thompson S. (1995) Going all the way: Teenage girls'tales of sex, romance and preganacy. New York: Hill \& Wang

Tiggemann M \& Slater A. (2014) Contemporary girlhood: Maternal reports on sexualized behaviour and appearance concern in 4-10 year-old girls. Body Image 11:396-403

Melby T. (2005). Asexuality gets more attention, but is it a sexual orientation? Contemporary Sexuality 39(11)1: 4-5 
Tolman DL \& McCleeland SI. (2011) Normative sexuality development in adolescence: A decade in review. Journal of Research on Adolescence 21(1):242-255

Tornello SL, Riskind RG \& Pattersson CJ. (2014) Sexual orientation and sexual and reproductive health among adolescent young women in the United States. Journal of Adolescent Health 54(2):160-168

Tsitsika A, Greydanus, D, Konstantoulaki E, Bountziouka V, Deligiannis I, Dimitrakopoulou et al. (2010) Adolescents dealing with sexuality issues: a cross sectional study in Greece. Journal of Pediatric Adolescent Gynecology 23(5):298-304

Tubman JG, Windle M \& Windle RC. (1996) Cumulative sexual intercourse among middle adolescents: problem behaviour precoursors and concurrent health risk behvaiours. Journal of Adolescent Health 18:182-191

Tydén T, Palmqvist M \& Larsson M. (2012) A repeated survey of sexual behaviour among female university students in Sweden. Acta obstetrica et gynecologica Scandinavia 91(2):215-219

Tydén T \& Rogala C. (2004) Sexual behaviour among young men in Sweden and the impact of pornography. International Journal of STD \& AIDS 15(9):590-593

Ungdomsstyrelsen. (2009) Jag syns. Jag finns. Unga om sexuell exploatering, prostitution och internet. I Ungdomssyrelsen Se mig. Unga om sex och internet. (From: See me. Young people on sex and the Internet. In the Swedish National Board for Youth Affairs) Stockholm: Ungdomssyrelsen

van Anders SM. (2012) Testosterone and sexual desire in healthy women and men. Archives of Sexual Behaviour 41(6): 147114-84

Valle AK, Røysamb E, Sundby J \& Klepp KI. (2009) Parental social position, body image, and other psychosocial determinants and first intercourse among 15- and 16-years olds. Adolescence 44(174):479-98 
Van den Berg SM, Setiawan A, Bartels M, Polderman TJC, van der Vaart AW \& Boomsma DI. (2006) Individual differences in puberty onset in girls: Bayesian estimation of heritabilities and genetic correlations. Behavior Genetics 36:261-270

Vance C. (1991) Anthropology rediscovers sexuality: A theoretical comment. Social Science Medicine 33(8):875-884

Våningssäng på bröllopsresan. En kartläggning av hur bra svenska företag är på att bemöta homo- och bisexualla kunder. (2007) Bunk bed on the honeymoon. A survey of how well Swedish company's is on addressing gay and bisexual clients. Frittfram.se Retried from:www.rfsl.se/public/ff_vaningssang.pdf

Welsh DP, Rostosky SS \& Kawaguchi MC. (2000) A normative perspective of adolescent girls'developing sexuality. In Travis CB \& White JW (Eds), Sexuality, society and feminism. Washington DC: American Psychological Association

Vogel J. (1998) Three types of European society. Retrieved from http://www.nnn.se/nmodel/europe3/europe3.htm\#Figure 1

Volbert R. (2000) Sexual knowledge of pre-school children. Journal of Psychology \& Human Sexuality 12:5-26

von Hofer H. (2003) Notes on crime and punishment in Sweden and Scandinavia. Report 2003:3. In S. Falck, H. von Hofer \& A. Storgaard (Eds.), Nordic Criminal Statistics 19502000 (284-312) Stockholm: Department of Criminology, Stockholm University

World health organization (WHO) Sexual and reproductive health. (2006) Retrieved from: www.who.int/reproductivehealth/topics/sexual_health/sh_definitions/en/

World health organization (WHO) Sexual and reproductive health. (2015) Retrieved from: www.who.int/maternal_child_adolescent/topics/adolescence/dev/en/ 
Wiekowski E, Hartsoe P, Mayer A \& Shortz J. (1998) Deviant sexual behaviour in children and young adolescents: Frequency and patterns. Sex Abuse 10:293-303

Ybarra MC, Mitchell KJ, Hamburger M, Diener-West M \& Leaf PJ. (2010) X-rated Material and perpetration of sexually aggressive behavior among children and adolescents: is there a link? Aggress behav (serial online) Avaible from: ULR: www.ncbi.nlm.nih.gov/pubmed/21046607

Ybarra ML, Mitchell KJ, Palmer NA \& Reisner SL. (2015) Online social support as a buffer against online and offline peer and sexual victimization among U.S. LGBT and non-LGBT youth. Child Abuse and Neglect 39:123-136

Zetterberg H. (1969) Om sexuallivet i Sverige. Värderingar, normer och beteenden i sociologisk tolkning. (About sexual life in Sweden-on values, norms and behaviour in a sociological frame) Stockholm: SOU 1969:2 



\section{Papers}

The articles associated with this thesis have been removed for copyright reasons. For more details about these see:

http://urn.kb.se/resolve?urn=urn:nbn:se:liu:diva-123029 